\title{
Links between observed micro-meteorological variability and land use patterns in the Highveld Priority Area of South Africa
}

\author{
Igor Esau $^{1,2,3^{*}}$, Philbert Luhunga ${ }^{4}$, George Djolov ${ }^{4}$, C. J. deW. Rautenbach ${ }^{4}$ \\ and Sergej Zilitinkevich ${ }^{1,3,5,6}$
}

${ }^{1}$ Nansen Environmental and Remote Sensing Center, G.C. Rieber Climate Institute, Thormohlensgt. 47, 5006, Bergen, Norway, e-mail: igore@nersc.no

${ }^{2}$ Centre for Climate Dynamics (SKD), Bergen, Norway

${ }^{3}$ Dept of Radiophysics, University of Nizhny Novgorod, Russia

${ }^{4}$ University of Pretoria, Department of Geography, Geoinformatics and Meteorology, Faculty of Natural and Agricultural Sciences, University of Pretoria 0002, South Africa, e-mail: george.djolov@up.ac.za

${ }^{5}$ Finnish Meteorological Institute, Helsinki, Finland PL 503 (Erik Palmenin aukio 1)

00101 Helsinki, Finland, e-mail: Sergej.Zilitinkevich@ fmi.fi

${ }^{6}$ Division of Atmospheric Sciences, University of Helsinki, Finland

* Corresponding author: Igor Esau, Nansen Environmental and Remote Sensing Center, Thormohlensgt. 47, 5006, Bergen, Norway, e-mail: igore@nersc.no 


\begin{abstract}
Links between spatial and temporal variability of Planetary Boundary Layer (PBL) meteorological quantities and existing land use patterns are still poorly understood due to the non-linearity of air-land interaction processes. This study describes the results of a statistical analysis of meteorological observations collected by a network of ten Automatic Weather Stations (AWSs). The stations were in operation in the Highveld Priority Area (HPA) of the Republic of South Africa during 2008 - 2010. The analysis revealed localization, enhancement and homogenization in the inter-station variability of observed meteorological quantities (temperature, relative humidity and wind speed) over diurnal and seasonal cycles. Enhancement of the meteorological spatial variability was found on a broad range of scales from 20 to $50 \mathrm{~km}$ during morning hours and in the dry winter season. These spatial scales are comparable to scales of observed land use heterogeneity, which suggests links between atmospheric variability and land use patterns through excitation of horizontal meso-scale circulations. Convective motions homogenized and synchronized meteorological variability during afternoon hours in the winter seasons, and during large parts of the day during the moist summer season. The analysis also revealed that turbulent convection overwhelms horizontal meso-scale circulations in the study area during extensive parts of the annual cycle.
\end{abstract}

Key words: Micro-meteorology, Planetary boundary layer, Air-land interactions, Statistical data analysis 


\section{Introduction}

It has been recognized (Pielke, 2001; Patton et al., 2005; Horlacher et al., 2012) that heterogeneity of land use has a significant impact on land-air interaction and atmospheric dynamics in the planetary boundary layer (PBL). Several studies (e.g. Esau and Lyons, 2002; Sogalla et al., 2006; Scanlon et al., 2007) have found strong connections between land use patterns and the largest scales of atmospheric turbulent convection. For instance, Scanlon et al. (2007) revealed a positive feedback to the atmospheric meso-scale and planetary boundary layer dynamics linked to the clustering of vegetation in arid areas of the Kalahari desert in southern Africa. Starting from homogeneously and randomly distributed vegetation, they arrived to strongly localized vegetation clusters in their model. The process has been attributed to a redistribution of atmospheric convective motions, and therefore, precipitation.

A major deficiency of such modeling studies is that the links between the atmospheric dynamics and land use types are implicitly incorporated into the corresponding (e.g. atmospheric convection and dynamical vegetation) model parameterizations. Hence, independent observationally based validation and calibration are required. A better understanding of the atmospheric dynamics on a multitude of spatial and temporal scales over a realistic heterogeneous landscape could be gained through the analysis of synchronous high-resolution meteorological observations collected by a dense network of Automatic Weather Stations (AWSs).

Statistical analysis of observations and their associated meteorological modeling is often disclosing non-linear and climatologically significant effects caused by turbulence selforganization and excitation of meso-scale circulations (land breezes) over different types of surface heterogeneity. For instance, Heerwaarden and Vila-Guerau de Arellano (2008) studied the sensitivity of PBL turbulent dynamics to surface heterogeneities with the aid of turbulence-resolving models, where the transport of specific humidity was varied. Their results clearly indicated that despite the higher temperature and lower surface relative humidity of warm land patches, the heterogeneity-induced convection facilitate 
the penetration of air parcels to higher elevations where additional condensation enhanced cloud formation. Horlacher et al. (2012) performed a combined statistical analysis on meteorological observations and the simulated output by two meso-scale models, and demonstrated greatly enhanced spatial variability of screen-level variables under stably stratified boundary layer conditions. This variability decreases with height, but at low levels (up to $10 \mathrm{~m}$ ) it manifested local temperature differences as large as $5^{\circ} \mathrm{C}$, which are significant and therefore important for agricultural and other social economic activities.

This study describes unique high-resolution synchronous observational data sets that were collected from February 2008 to December 2010 by two independent dense AWS networks deployed in the Highveld Priority Area (HPA) of the Republic of South Africa (Figure 1). This network of stations is significantly larger, and more diverse, than networks used in previous studies (e.g Taylor et al., 2007; Washington et al., 2005; Laakso et al., 2010; Horlacher et al., 2012). The statistical data analysis focuses on the study of micro-meteorological spatial and temporal variability of surface air temperature, relative humidity and wind speed. Using co-variability as a characteristic of the impact of land use and other heterogeneities on the atmospheric turbulent dynamics, this study attempts to reveal patterns of homogenization, localization and enhancement of the nearsurface atmospheric dynamics. These patterns are still poorly studied and therefore not accounted for in the PBL parameterizations used in many meteorological models.

Since the HPA is a highly industrialised area accounting for about $75 \%$ of South Africa's industrial output, the region is the source of significant atmospheric pollution (e.g. Tyson et al., 1988; Laakso et al., 2010). Sources of about $90 \%$ of the South African nitrogen oxide emission are located in the HPA. The concentration of such pollutants depends on the micro-meteorological variability, which could be used as a proxy characteristic for turbulent dispersion and meso-scale meteorological transport of admixtures. Human health in the HPA, especially the health of children, has been found to be already significantly affected by atmospheric pollution (Alberts, 2011). Alberts (2011) has, however, concluded that a quantification of the effect of ambient air pollution on human 
health was problematic due to the lack of proper high resolution meteorological information. This study could provide such information for future health risk assessment and life quality research.

The manuscript is structured in five sections. The following section (Section 2) describes the study area and the data collected. Section 3 describes the methodology of analysis, while results of the study are discussed in Section 4. In it the applications and limitations of the results are also considered. Conclusions from the study are summarised in Section 5 .

[INSERT FIGURE 1 HERE]

\section{Description of the study area and observations}

\section{a. Geography}

The HPA has been intensively studied during several decades (e.g. Von Gogh et al., 1982; Tyson et al., 1988; Jury and Tosen, 1989; Held et al., 1996; Freiman and Tyson, 2000; Tyson and Gatebe, 2001; Freiman and Piketh, 2003; Collett et al., 2010; Laakso et al., 2010). The HPA is located in the South Africa Highveld region $\left(25^{\circ} \mathrm{S}\right.$ to $27^{\circ} \mathrm{S} ; 28^{\circ} \mathrm{E}$ to $\left.30^{\circ} \mathrm{E}\right)$. It extends across the eastern parts of the urbanized Gauteng Province and the country's largest cities (Pretoria and Johannesburg), and falls also in the Free State and Mpumalanga Provinces where it occupies an plateau of about $30000 \mathrm{~km}^{2}$ with an altitude of about $1400 \mathrm{~m}-1700 \mathrm{~m}$ above mean sea level. In general, the surface of the plateau is rather flat but surface morphology is very heterogeneous. About $70 \%$ of the HPA is covered by grassland, while the rest is utilised for agricultural (maize, cattle and sheep, crop production, dairy farming), urban and industrial activities. Figure 2 exemplifies surface heterogeneity in the HPA. It shows the Normalized Digital Vegetation Index (NDVI) for a $20 \mathrm{~km}$ by $20 \mathrm{~km}$ patch within the HPA obtained from the Landsat platform 7 satellite on 3 July 2006. The normalized spectra for the bands 2, 3, 5 and 7 of the satellite image revealed maxima of variability on scales of $5-10 \mathrm{~km}$. The normalized 
brightness spectrum in band 4 reveals the maximum on larger scales $(10-20 \mathrm{~km})$, whereas the spectrum in band 1 reveals the maximum on much smaller sub-kilometer scales. Maxima in the variability on scales $5-20 \mathrm{~km}$ are easily associated with the visually observed variability in land use types in Figure 2.

\section{[INSERT FIGURE 2 HERE]}

\section{b. Climate}

Over South Africa as a whole, and over the HPA in particular, the upper air (above 700 $\mathrm{hPa}$ pressure level) general circulation of the atmosphere is anti-cyclonic throughout the year (Held et al., 1996). This is as a result of descending meridional Hadley circulation that dominates in the subtropics. During the austral summer season (September February), however, solar radiation absorption at the surface facilitates the development of near-surface troughs in the region dominated by upper air subsidence. On the synopticscale, clockwise circulation around these troughs normally lead to moisture advection from the tropics, which is a major contributor to summer rain when local instabilities result in the development of convective thunderstorms (Freiman and Tyson, 2000). During the dry austral winter season (March - August) anti-cyclonic circulation dominates throughout the entire troposphere (Jury and Tosen, 1989). However, vertical lift associated with eastward cold front propagation might lead to winter rain along the south-western and southern coastlines. A ridging high pressure system, which extends from the Atlantic Ocean high pressure system and propagates eastwards along the South African coastline behind cold fronts, might also result in precipitation along the southern and eastern coastlines. This creates favourable conditions for cloud development against the eastern escarpment.

The HPA climate is found to be cooler than the climate of other areas of similar latitude, which is mainly due to the high altitude of the HPA. The weather is characterised by hot summer daytime temperatures $\left(25\right.$ to $\left.32^{\circ} \mathrm{C}\right)$, and spectacular late afternoon thundershowers. Winter daytime average temperatures are cooler $\left(15\right.$ to $\left.19^{\circ} \mathrm{C}\right)$, while 
night time temperatures often drop below freezing point, which often leads to morning frost. During winter, temperature inversions occur almost every night at the surface, while elevated inversions are occurring with high frequency (Von Gogh et al., 1982; Freiman and Tyson, 2000; Becker, 2005). As a matter of fact elevated inversions occur on $60 \%$ of all days at a mean altitude of $1700 \mathrm{~m}$ above ground level, and with a depth and strength of just under $200 \mathrm{~m}$ and $1.5^{\circ} \mathrm{C}$, respectively. In winter, the depth of the surface inversion varies from 300 to $500 \mathrm{~m}$ at around sunrise, which is the time of maximum depth and when the average strength of the inversion is about $5-6^{\circ} \mathrm{C}$. In summer, surface inversions are of approximately the same depth, but with strength of less than $2^{\circ} \mathrm{C}$. Tyson et al. (1988) presented climatological data on the PBL stability regime at the city of Bloemfontein which reveals the following frequency appearance at midday: stable (25\%), unstable (74\%) and inversion (1\%), and the following frequency appearance during midnight: stable (19\%), unstable (2\%), inversion (79\%).

HPA precipitation, which ranges from 600 - 800 mm per annum, has its maximum during December to January (the mid-austral summer season). Frost occurs regularly during winter months and ranges from about 30 days in the Mpumalanga Province, to about 70 days in the southern Free State Province. Winds are highly variable but easterly and westerly winds are more prevalent. Closer to the mountain ranges along the eastern escarpment the incidence of frost is probably even higher. Over higher lying areas snow events are not uncommon.

\section{c. Micro-Meteorological Experiment in the Highveld Priority Area (MMEH)}

The HPA is relatively densely covered with measurements stations. However, a large part of the observational data is proprietary and cannot easily be obtained. A part of the available data are scattered over a larger area, and therefore, are less useful for the characterization of micro-meteorological variability on spatial scales of up to $20 \mathrm{~km}$. In order to overcome these difficulties related to the homogenization of the available data sets, five AWSs were deployed in the HPA during a Norway-South Africa bilateral research project. The data collected by these stations constitute the Micro-Meteorological 
Experiment in the Highveld (MMEH) data set that is used in this study. The MMEH AWSs (identified by the symbol "S") have been deployed in rural and agricultural areas. In addition, the South African Department of Environmental Affairs (DEA) provided data collected from another five AWSs (identified by the symbol " $D$ ") that were placed over a wider area as the MMEH AWSs in the HPA (see Figure 1). The DEA data set is very similar to the MMEH data set, although some systematic differences could be observed due to the preferable location of the DEA AWSs near settlements. Table 1 lists the 10 meteorological stations with their geographic coordinates. Table 2 gives the geodesic distances between the stations.

The MMEH AWSs made use of Davis Vantage Pro 2 instrumentation (see Application Note $N^{0} 30$ for technical information), and were equipped with a pressure sensor, temperature and humidity sensors, a wind anemometer, a rain collection gauge and a solar radiation sensor. The Davis Vantage Pro 2 instruments were chosen due to their low price and relatively high accuracy in a regime of autonomous data collection. This type of equipment has already successfully been used in African conditions (e.g. during the Bodele Experiment: BodEx-2005) conducted in Chad (Giles, 2005; Washington et al., 2005), and elsewhere in the world (e.g. the Bergen municipality (Norway) installed and operates 55 Davis Vantage Pro 2 AWSs to monitor weather conditions). The DEA AWSs were based on a more permanent installation in a $3 \mathrm{~m} \mathrm{x} 2 \mathrm{~m} \times 2.4 \mathrm{~m}$ shelter and a $10 \mathrm{~m}$ mast for wind measurements on a concrete plinth with $1.8 \mathrm{~m}$ palisade for security. The DEA AWSs are equipped with RM Young instrumentation (RM Young, Traverse City, USA) measuring wind speed and direction, ambient air temperature, relative humidity, rainfall, solar radiation and barometric pressure.

The MMEH and DEA data were collected from the beginning of February 2008 through to the end of December 2010. Data samples were recorded every 10 minutes (144 samples per day when the completeness was 100\%). As commonly experienced with unattended AWS observations, the collected data sometimes had significant gaps, mostly due to technical problems with the stations (see Table 1). Therefore, the joint use of both data sets could be beneficial as it would greatly improve the data coverage during the 
considered period. There are two periods continuously covered with observations: (1) the austral winter during June and July 2009; (2) the austral summer during January and February 2009. In addition, there are a period during August and December 2008 when all MMEH AWSs were recording without any problems.

\section{Methodology}

Data sets collected from a dense network of synchronous AWSs only very recently became accessible for statistical analysis, and there are therefore no commonly used methods or procedures available to provide a complete and unambiguous statistical interpretation of inter-AWS relationships. Literature surveys, however, revealed a large diversity of suggested methods and routines, but many of these cannot be used consistently for informative analyses of the data of this study. This study will therefore be confined to a multi-scale variability analysis using a convenient modification of the approach followed by Harzallah and Sadourny (1995) and Ting et al. (2009). The method seeks to quantify contributions of externally forced variability as well as internal variability in the total data variance. The externally forced variability is defined as variability of an observed meteorological parameter, e.g. $u$, synchronized in the data from all stations in a data set. Correspondingly, the internal variability is associated with variability in data specific to the given station, and can therefore be obtained from interAWS variability at any given time. If there exists any significant effect of land use heterogeneity on the PBL, it should be reflected as enhanced internal variability as compared to the forced variability.

Data collected by the spatially distributed network of AWSs in the HPA are beneficial for studying external versus internal variability, as they can be processed with two variants of the multi-scale analysis, conventionally called spatial scale analysis and Root Mean Square (RMS) analysis.

a. Spatial scale analysis 
Consider a pair of stations $i$ and $j$ with a distance $d_{i j}$ between them (see Table 2). A spatial fluctuation of a parameter $u$ for this pair of stations is defined as

$u_{i}^{\prime}=u_{i}-\left(u_{i}+u_{j}\right) / 2$

The time averaged variability is defined as

$M_{u u}(i, j, n)=\left[\overline{u^{\prime} u^{\prime}}\right]_{i j}=\frac{1}{2} \overline{\left(u_{i}^{\prime} u_{i}^{\prime}+u_{j}^{\prime} u_{j}^{\prime}\right)}, \quad$ for all $i>j$

where $n=1 \ldots 144$ denotes the number of the data samples counted since midnight within each diurnal cycle (for each day there were in total 144 data samples separated by a 10 minute interval). The over-bars denote time averaging for each $n$ done over the entire considered period of observation. In this study, 61 day period in summer and 60 day period in winter seasons were considered. Here the focus quantity is maximum variability, which is defined as

$\overline{U^{\prime} T^{\prime}}(i, j)=\max _{n=1 . .144}\left(M_{U T}(i, j, n)\right)$

It characterizes the maximum variability of the horizontal temperature flux $\left(\overline{U^{\prime} T^{\prime}}\right)$. Variability of the horizontal relative humidity flux $\left(\overline{U^{\prime} R^{\prime}}\right)$ and the horizontal momentum flux $\left(\overline{U^{\prime} U^{\prime}}\right)$ are obtained in the same manner. It is reasonable to expect that the flux given by Eq. (3) maximize on certain spatial scales, as fluctuations defined by Eq. (1) might increase with an increase in the distance $d_{i j}$, while correlations between observed data from such stations might decay.

At a large scale, only the external forced variability, which is the same for all stations in the area, will determine residual horizontal flux values. The decay of these fluxes with increasing $d_{i j}$ is, however, not necessarily monotonic. If there are significant interactions 
between the land use scales and the scales of the atmospheric dynamics, the fluxes may level off or even enhance for a certain range of scales. The next section will demonstrate that this is in fact the case for the MMEH, as well as for DEA data recorded in the HPA. Such an enhancement of turbulent exchange over heterogeneous surface was previously referred to as a resonant response (Roy et al., 2003; Patton et al., 2005; Esau, 2007; Robinson et al., 2008). Such response is expected within the range of normalized scales 1 $<d_{i j} / h<9$, where $h$ denotes the PBL depth. The lower limit of scales is more relevant to initial stages of the PBL convection, whereas the upper limit is more relevant to well developed convection (Robinson et al., 2008). Taking $h=2$ to $3 \mathrm{~km}$ in the HPA (Freiman and Tyson, 2000), fluxes should peak at distances of $d_{i j}=5$ to $30 \mathrm{~km}$. These spatial scales are rather similar to the typical land use heterogeneity scales in Figure $2 \mathrm{~b}$. Unfortunately, the scales smaller than $10 \mathrm{~km}$ are only marginally resolved in the available data sets.

\section{b. Root Mean Square (RMS) analysis}

In RMS analysis the mean variability of a parameter $u$, which is determined for each station over all time intervals, is compared with the mean variability of $u$, which is determined at each time interval over all stations. Mathematically, if $u(i, t)$ is a matrix at each sampling interval, where the row index $i=1, \ldots, N$ runs over stations and the column index $t=1, \ldots, T$ runs over time intervals, the temporal and spatial RMS could be defined as

$$
\begin{aligned}
& \sigma_{u}^{\text {time }}(n)=\sqrt{\left\langle\left\langle(u-\bar{u})^{2}\right\rangle\right.}, \\
& \sigma_{u}^{\text {station }}(n)=\sqrt{\left\langle\overline{\left.(u-\langle u\rangle)^{2}\right\rangle},\right.}
\end{aligned}
$$

where $\langle u\rangle(t, n)=\frac{1}{N} \sum_{i} u(i, t, n)$ and $\bar{u}(i, n)=\frac{1}{T} \sum_{t} u(i, t, n)$. 
In order to study diurnal cycle of interactions between land use and PBL dynamics, time averaging was achieved independently for each of the data sampling moments $n$ across all days available in each data set (60 or 61 days for $100 \%$ completeness of a station's data).

Both measures, $\sigma_{u}^{\text {station }}$ and $\sigma_{u}^{\text {time }}$, may rise and fall within the diurnal cycle. Moreover, one may be consistently smaller or larger than the other. Useful information could be extracted from their relative change within the diurnal cycle as defined by the following measures:

$R_{u}(n)=\frac{\sigma_{u}^{\text {station }}(n)}{\sigma_{u}^{\text {station }}(n)+\sigma_{u}^{\text {time }}(n)}$,

$D_{u}(n)=\left(\sigma_{u}^{\text {station }}(n)-\overline{\sigma_{u}^{\text {station }}(n)}\right)-\left(\sigma_{u}^{\text {time }}(n)-\overline{\sigma_{u}^{\text {time }}(n)}\right)$.

Here the over-bar denotes averaging over all the diurnal sampling intervals $n$.The ratio, $R_{u}$, indicates the relative significance of the internal (local) variability at the stations versus total variability. It should not be confused with the fraction of total variability, which is explained by the internal variability. For small ensembles of data sets $(N<20)$ with large internal variability, such a fraction would be estimated with a significant error (Ting et al., 2009). The difference of the normalized RMS, $D_{u}$, indicates the relative importance of changes in the external and internal variability across the diurnal cycle. A reduction of $D_{u}$, in particular to negative values, indicates spatial homogenization, and therefore diminishing internal variability. Vice versa, an increase of $D_{u}$ indicates that the internal variability become more pronounced, which suggests an increased coupling between local land surface features and atmospheric PBL dynamics and a decreasing coupling to the large scale dynamics of the free troposphere, correspondingly. 


\section{Results}

\section{a. Externally forced variability versus internal variability}

In this study, the methods proposed for spatial scale and RMS analyses mutually complement each other. The former select the horizontal scale of the optimal land use atmosphere coupling while the latter show the change of the coupling strength within a typical diurnal cycle for both winter and summer seasons.

Figure 3 denotes results of the spatial scale analysis as applied to the available data sets. Previously published works (Patton et al., 2005; Esau, 2007; Robinson et al., 2008) suggested that the horizontal flux given in Eq. (3) should be enhanced on the scales 5 $30 \mathrm{~km}$, in the event of PBL development over a homogeneous surface. At the same time, Figure 2 revealed that the typical range of NDVI variability is $7-20 \mathrm{~km}$. Thus, the range of scales of the expected resonant response in PBL dynamics partially overlaps with the range of scales of the observed surface morphology variations. In the winter season, certain enhancements in $\overline{U^{\prime} T^{\prime}}$ and $\overline{U^{\prime} R^{\prime}}$ was found within the range of scales $30-50$ $\mathrm{km}$. Similar spatial scales of convection enhancement were found in the AMMA studies (Taylor et al., 2002; 2007) and studies by Roy et al. (2003) in the Amazon forest area. Although the number of data sets in the constructed ensembles is small (5 for each of the MMEH and DEA data sets and only 8 for a composite ensemble as all MMEH and all DEA stations have been never observing simultaneously), the flux enhancement in the range of scales is rather consistent and as large as 0.5 of the maximum normalized flux magnitude. It was found that the maximum variability was typically reached between 1316 hours of Local Solar Time (LST).

During the summer season, flux enhancement is less pronounced and shifted to larger scales of $40-60 \mathrm{~km}$. This range of scales seems to be unrelated to NDVI surface heterogeneity, but could be connected to developing moist convection and cloud clustering - as will be discussed below. The maximum variability was typically reached 
between 16-20 hours of LST, which is significantly later than the maximum during the winter season.

\section{[INSERT FIGURE 3 HERE]}

Diurnal cycles of the winter and summer RMS values are shown in Figures $4-7$. A common picture of the developing daytime convection (e.g. Zilitinkevich et al., 2006) predicts a breakdown in nocturnal inversions, which prevents both vertical and horizontal mixing of near-surface air, and the development of a deep, well-mixed convective layer, which is well mixed in the core, but which still may have some local dependences within the layer of super-adiabatic gradients near the surface. The atmospheric convection is, however, self-organized. Although near surface air is well-mixed on the horizontal scales (up to the scale of convective cells), there could still be a considerable deference between these cells (Esau and Lyons, 2002; Junkermann et al., 2009) that is determined by land surface heterogeneities on larger scales. The growth of a convective cell as observed during the course of the day results in successive mixing of heterogeneities on increasingly larger scales. The RMS analysis may therefore reveal an enhancement of convection on certain scales when the turbulence (or meso-scale circulations) in the convective cells becomes more coupled to surface characteristics. This coupling will occur at certain hours of LST, as horizontal scales increase as $l \propto t^{1 / 2}$.

In this study, the ensemble of all MMEH and DEA station data is considered. Inspection of the individual MMEH and DEA data sets revealed an acceptable qualitative and quantitative similarity to this ensemble, and hence individual data sets will not be considered. Diurnal variability of the incoming solar radiation is illustrated in Figure 4. This figure is useful to test the proposed interpretation of the RMS analysis as the diurnal course of incoming solar radiation is well-known. The solar radiation RMS is defined by the presence of clouds with horizontal scales of smaller than the distance between stations. These clouds might help to detect the size of the convective cells, although convection might not create clouds in a dry atmosphere. At sunset and sunrise, the solar radiation RMS will also be defined by local surface properties such as trees, houses and 
the orientation of the terrain slope. Figure 4 suggests that local surface properties and clouds have little effect on the RMS during summer, as cloud clusters would typically occupy the whole HPA area. During winter, the effect is more pronounced, indicating smaller cloud sizes and longer periods associated with low sun angles.

\section{[INSERT FIGURE 4 HERE]}

Figures 5-7 shows results from the RMS analysis of surface air temperature, relative humidity and wind speed. With respect to the scope of this study, the most interesting transition occurs during the winter season. The local regime dominated by internal variability is identified during the night and morning times. The internal variability is about $55-65 \%$ of the sum of the RMS in this regime with the average difference between stations reaching: (1) $3{ }^{\circ} \mathrm{C}$ in temperature; (2) $10 \%$ in relative humidity; (3) but only $0.2 \mathrm{~m} \mathrm{~s}^{-1}$ in wind speed. These numbers clearly identify the expected effect of stable stratification and reduced horizontal mixing. The wind speed RMS reaches its maximum during the afternoon hours (16 LST). This maximum could be interpreted as the time when the horizontal size of convective cells reached their resonance interval of scales. It means that turbulent convection is enhanced by meso-scale land breeze motions generated by the heterogeneity of land use types. This enhancement may result in the local raise in PBL heights to above the lifted condensation level, which then could results in cloud development. This interpretation is consistent with Figure 4, as clouds increase the incoming solar radiation RMS, and with Figure 6, as no particular feature in the relative humidity RMS is found.

The summer season is characterized by much smaller internal variability, where the ratio $R_{u}$ drops to between $35 \%-45 \%$. The wind speed RMS difference reaches its maximum in the late morning hours (10 LST) and then significantly reduces as the day progresses. Taken in account that the summer PBL is normally deeper, and develops faster than the winter PBL, the time shift of the wind speed RMS maximum could be interpreted as similar to the discussed enhancement of the turbulent convection that was observed at 16 LST in wintertime. The subsequent growth of the PBL destroys the resonance between 
turbulent and breeze circulations, which then might lead to smaller wind speed RMS values.

[INSERT FIGURE 5 HERE]

[INSERT FIGURE 6 HERE]

[INSERT FIGURE 7 HERE]

\section{b. Discussion}

One of the most important criteria for the quality of statistical analysis is the number of independent samples and data sets considered, which then constitutes the statistical ensemble. The MMEH and DEA data sets covered the temporal variability of the HPA climate relatively well. In this study 144 time samples were considered at each station for each day with a $100 \%$ completeness in observation records - there were 60 (or 61) continues days of observations. There were two periods during the summer seasons, and one period during the winter season with observations representing the majority of stations. In contrast to the temporal variability, the spatial variability of the HPA climate was covered much worse. There were only 3 stations in the MMEH data set, and 5 stations in the DEA data set, that have been recorded simultaneously. Thus, the ensemble consisted only of 8 members. This is not enough for quantifying the statistical confidence of the derived dependences and to running more sophisticated variants of the analysis (e.g. the principal orthogonal decomposition analysis or the Bayesian probability analysis). This objective limitation of the study is unlikely to be addressed in the near future since a dense network of AWSs is expensive to erect and maintained. Similar problems are encountered by the climate model community where the number of model ensembles is of the same order of magnitude.

To overcome these limitations in rigorous statistical analysis, the focus of discussion is shifted from quantitative dependences to qualitative measures. As common in the climate 
model community (e.g. Ting et al., 2009), this study considers dissimilarity of temporal variations in the ensemble members. With respect to the spatial scale analysis, one could observe that the scattered data reach the maximum (or minimum) of horizontal flux in the same range of scales for each data set, as well as in the blending of these data sets. Although it is difficult to quantify the degree of enhancement of atmospheric motions in the PBL, it is very likely that scales of the enhancement were indentified correctly in this study, and that these enhancements are not random. Future work on this will necessarily involve high-resolution numerical modeling as it has already been applied elsewhere (e.g. Esau and Lyons, 2002).

The enhancement of variability found in this study has been interpreted as a strengthening of the turbulent convection by meso-scale breeze motions. Another physically plausible cause of enhancement could be linked to the cloud system development. According to Blamey and Reason (2012), the meso-scale convective storms that develop in the HPA during summer have a general initiation time of 13 - 19 LST. It corresponds well to this study's afternoon maxima in temperature $\sigma_{T}^{\text {time }}, D_{T}$ and similar maxima in the relative humidity. It was also found that the wind speed RMS consistently increases as convection developed. The horizontal scale of storms was found to be $200-$ $300 \mathrm{~km}$, which covers the entire area of observations. Hence, convective storms did not generate internal variability in meteorological quantities, with the exception for wind speed, which is affected by sub-cloud micro-fronts. This is different to the RMS behavior found during wintertime when all quantities exhibit coherent fluctuations within the diurnal cycle.

\section{Conclusions}

An analysis of observational data collected from two independent networks of AWSs in the HPA of South Africa, are presented. Meteorological quantities were recorded with a high time frequency (sampling every 10 minutes) in a synchronous mode of operation. This allowed for the utilization of the ensemble of data sets, not only to characterize time series variability, but also spatial micro-meteorological variability and their mutual 
interference. Although the ensemble consists of only eight members placed at distances of $10-100 \mathrm{~km}$ from each other, it is still comparable with typical previously used ensembles from regional and climate model simulations and even superior to them if the horizontal resolution of AWS distribution is considered.

In this study the statistical analysis of the prepared ensemble obtained from AWS data sets was aimed at investigating variability at different time and spatial scales. The analysis was seeking for an enhancement in PBL dynamics through increased meso-scale circulation under conditions of surface heterogeneity in the HPA. Such an enhancement was indeed found in the data on scales of $30-50 \mathrm{~km}$ (during winter seasons) and $40-60$ $\mathrm{km}$ (during summer seasons). These scales, however, are somewhat larger than scales visually identified on the NDVI Landsat images. Hence, although the links between atmospheric circulation enhancement and surface heterogeneity were identified qualitatively, quantification of such links still requires high resolution numerical model studies.

The strongest evidence of land use - atmosphere resonant coupling at certain scales was derived from the diurnal evolution of the RMS transition from internal (local) to externally forced variability regimes. The results suggest that nocturnal, and especially wintertime, variability is shaped by local surface properties. The development of a deeper convective PBL homogenized internal variability forcing synchronous variations of the meteorological quantities across the stations. As the growing convective cell increases in size to the scale of meso-scale circulations a kind of resonance interaction between the convective and meso-scale motions occurred that enhanced the horizontal fluxes.

It is known that interactions between the surface layer's atmospheric dynamics and land use heterogeneity are strongly non-linear and complex. This is one of the reasons why these interactions are not satisfactory included in meteorological or climate models. Results from this study provide solid and sound observational material for further model development, as well as for a more accurate interpretation of regional climate change. A 
more applied utility of the analysis is seen in the optimization of land use, the calibration of satellite remote sensing data and the facilitation of climate adaptation.

\section{Acknowledgements}

The authors would like to acknowledge the bilateral Norway-South Africa project 180343/S50 "Analysis and the Possibility for Control of Atmospheric Boundary Layer Processes to Facilitate Adaptation to Environmental Changes" co-funded by the South African National Research Foundation (NRF) and the Norwegian Research Council (NRC). A significant part of this work has been developed under the NRC project 191516/V30 "Planetary boundary layer feedback in the Earth's Climate System", under the European Research Council Advanced Grant, FP7-IDEAS, 227915 "Atmospheric planetary boundary layers: physics, modeling and its role in the Earth system", and under a grant from the Government of the Russian Federation (project code 11.G34.31.0048). The Authors are grateful to the DEA, and in particular to Xolile Ncipha, for making the DEA data available. The authors are also grateful to all farmers who gave permission for the deployment of AWSs on their land and who assisted in the collection of data. 


\section{References}

Alberts, P.N., 2011. Baseline assessment of child respiratory health in the Highveld Priority Area, dissertation at School of Health Systems and Public Health, University of Pretoria, $80 \mathrm{pp}$.

Application Note, $N^{\circ} 30$ : Reporting quality observations to NOAA and other weather observation groups, Rev B 3/4/08, available from http://www.davisnet.com/product_documents/weather/app_notes/apnote_30.pdf (last accessed 21 March 2011)

Becker, S., 2005. Thermal structure of the atmospheric boundary layer over the South African Mpumalanga Highveld, Clim. Res., 29, 129-137

Blamey, R.C., Reason, C.J.C., 2012. Mesoscale convective complexes over Southern Africa, J. Climate, 25, 753-766

Collett, K.S., Piketh, S.J., Ross, K.E., 2010. An assessment of the atmospheric nitrogen budget on the South African Highveld, South African J. of Sci., 106(5-6), 1 - 9.

Esau, I., and T.J. Lyons, 2002: Effect of sharp vegetation boundary on the convective atmospheric boundary layer, Agricult. Forest Meteorol., 114(1-2), 3-13

Esau, I., 2007: Amplification of turbulent exchange over wide Arctic leads: Large-eddy simulation study, J. Geophys.l Res., 112, D08109, doi:10.1029/2006JD007225

Freiman, M.T., Piketh, S.J., 2003. Air transport into and out of the industrial Highveld region in South Africa, J. Applied Meteorol., 42, 994 - 1005.

Freiman, M.T. and P.D. Tyson, 2000: The thermodynamic structure of the atmosphere over South Africa: Implications for water vapour transport, Water SA, 26(2), 152158

Harzallah, A., Sadourny, R., 1995. Internal versus SST-forced atmospheric variability as simulated by an atmospheric general circulation model, J. Climate, 8, 474-495.

Van Heerwaarden, C.C. and J. Vilà-Guerau de Arellano, 2008: Relative humidity as an indicator for cloud formation over heterogeneous land surfaces, J. Atmos. Sci., 65(10), 3263 - 3277.

Held, G., Scheifinger, H., Snyman, G.M., Tosen, G.R., Zunckel, M., 1996. The climatology and meteorology of the Highveld (Chapter 9 in: Air pollution and its 
impacts on the South African Highveld, G. Held, B.J. Gore, A.D. Surridge, G.R. Tosen, C.R. Turner and R.D. Walmsley, eds), 60-71, Environmental Scientific Association, Cleveland, $144 \mathrm{pp}$.

Horlacher, V., Osborne, S. and J.D. Price, 2012: Comparison of two closely located meteorological measurement sites and consequences for their areal representability, Boundary-Layer Meteorol, 142, 469-493

Giles, J., 2005: Climate science: The dustiest place on Earth, Nature, 434, 816-819

Von Gogh, R.G., Landenberg, H., Brassel, K., Danford, I., 1982. Dispersion climatology and characteristics of sulphur dioxide pollution in Eastern Transvaal Highveld, ATMOS/82/3, Atmospheric Science Division, CSIR, Pretoria, 117 pp.

Junkermann, W., Hacker, J., Lyons, T., Nair, U., 2009. Land use change suppress precipitation, Atmos. Chem. Phys., 9, 6531 - 6539

Jury, M.R. and G.R. Tosen, 1989: Characteristics of the winter boundary layer over the African Plateau: $26^{\circ} \mathrm{S}$, Boundary-Layer Meteorol, 49(1-2), 53-76

Laakso, L., Vakkari, V., Laakso, H., and 18 co-authors, 2010. South African EUCAARI - measurements: a site with high atmospheric variability, Atmos. Chem. Phys. Discuss., 10, $30691-30729$.

Patton, E.G., Sullivan, P.P., and C.-H. Moeng, 2005: Influence of idealized heterogeneity on wet and dry planetary boundary layers coupled to the land surface, J. Atmos. Sci., 62, 2078-2097

Pielke, R.A., 2001: Influence of the special distribution of vegetation and soils on the prediction of cumulus convective rainfall, Rev. Geophys., 39, 151-178

Robinson, F.J., Sherwood, S.C., Li, Y., 2008. Resonant response of deep convection to surface hot spots, J. Atmos. Sci., 65, 276-286.

Roy, S.B., Weaver, C.P., Nolan, D.S., Avissar, R., 2003. A preferred scale for landscape forced mesoscale circulations?, J. Geophys. Res., 108(D22), 8854, doi:10.1029/2002JD003097

Scanlon, T.M., Caylor, K.K., Levin, S.A., and I., Rodriguez-Iturbe, 2007: Positive feedbacks promote power-law clustering of Kalahari vegetation, Nature, 449, 209-212 
Sogalla, M., Krüger, A. and M. Kerschgens, 2006: Mesoscale modelling of interactions between rainfall and the land surface in West Africa, Meteorology and Atmospheric Physics, 91, 211-221

Taylor, C.M., Lambin, E.F., Stephenne, N., Harding, R.J., Essery, R.L.H., 2002. The influence of land use change on climate in the Sahel, J. Climate, 15, 3615-3629.

Taylor, C.M., Parker, D.J., Harris, P.P., 2007. An observational case study of mesoscale atmospheric circulations induced by soil moisture, Geophys. Res. Lett., 34, L15801, doi:10.1029/2007GL030572

Ting, M., Kushnir, Y., Seager, R., Li, C., 2009. Forced and internal Twentith-Century SST trends in the North Atlantic, J. Climate, 22, 1469-1481

Tyson, P.D., Kruger, F.J., Louw, C.W., 1988. Atmospheric pollution and its implications in the Eastern Transvaal Highveld. National Scientific Programmes Unit: CSIR, SANSP Report 150, pp 123

Tyson, P.D., Gatebe, C.K., 2001. The atmosphere, aerosols, trace gases and biogeochemical change in southern Africa: A regional integration, South African J. of Science, 97, 106-118.

Washington, R., Todd, M.C., Engelstaedter, S., Mbainayel, S., and F. Mitchell, 2005:

Dust and the Low Level Circulation over the Bodélé Depression, Chad: Observations from BoDEx 2005, J. Geophys. Res., 111(D3), D03201.

Zilitinkevich, S.S., Hunt, J.C.R., Grachev, A.A., Esau, I., Lalas, D.P., Akylas, E., Tombrou, M., Fairall, C.W., Fernando, H.J.S., Baklanov, A., Joffre, S.M., 2006. The influence of large convective eddies on the surface layer turbulence, Quarterly J. Royal Meteorol. Soc.,132, 1423-1456 


\section{Figure captions}

Figure 1. Digital elevation map of the Highveld Priority Area (HPA) in the Republic of South Africa. The map is based on the ASTER data base (http://www.gdem.aster.ersdac.or.jp/index.jsp). The horizontal data resolution is 1 arcsec ( $30 \mathrm{~m}$ along longitude). Color shading gives the elevation in meters above mean sea level (scale bar at the right side). The Automatic Weather Stations (AWSs) deployed in the HPA micro-meteorological experiment - MMEH (S1 - S5: circles), DEA (D1 - D4: squares). Other stations (diamond and star) provide regular meteorological data in the area.

Figure 2. The Normalized Digital Vegetation Index (NDVI) for the tile e29s 26 as obtained by the Landsat platform 7 with the sensor ETM+ at 03 July 2006. Pixel size = $30 \mathrm{~m}$. The size of the shown area is $20.6 \mathrm{~km}$ by $20.6 \mathrm{~km}$. The data source is the FAO FRA Landsat Imagery Database http://globalmonitoring.sdstate.edu/projects/fao/index.html. Typical elements of surface heterogeneity are seen as: (1) green and yellow patches - agricultural fields (wheat and maze); (2) gray and black patches - coal carriers; (3) blue patches - water reservoirs; (4) magenta patches - build-up areas; and (5) reddish and grayish patches - natural bush and harvested fields.

Figure 3. Variation of the normalized horizontal temperature flux $\overline{U^{\prime} T^{\prime}}$ (a,b) and the normalized horizontal relative humidity flux $\overline{U^{\prime} R^{\prime}}$ (c,d) as obtained through Eq. (3) as a function of the distance between stations. The squares show fluxes obtained for the DEA data set; circles from the MMEH data set; diamonds from the mixed DEA (one station) MMEH (another station) data set. The bin-averaged dependence is shown by the black curve. Panels a and c show variation during the austral summer season and panels $\mathrm{b}$ and $\mathrm{d}$ variation during the austral winter season.

Figure 4. Diurnal evolution of: (1) the RMS values for incoming short wave solar radiation, $\sigma_{S}^{\text {time }}$ (black dots) after $\mathrm{Eq}(4)$ and $\sigma_{S}^{\text {station }}$ (white circles) after Eq (5); (2) the 
ratio of variability $R_{S}$ after Eq. (6); (3) the normalized RMS values $\sigma_{S}^{\text {time }}-\overline{\sigma_{S}^{\text {time }}}$ (black dots) and $\sigma_{S}^{\text {station }}-\overline{\sigma_{S}^{\text {station }}}$ (white circles); (4) and their difference $D_{S}$ after Eq. (7). Panels $\mathrm{a}$ and $\mathrm{b}$ present the diurnal cycle for the austral summer and austral winter seasons, respectively.

Figure 5. The same as in Figure 4 but for RMS values of near-surface air temperature.

Figure 6. The same as in Figure 4 but for RMS values of relative humidity.

Figure 7. The same as in Figure 4 but for RMS values of wind speed. 


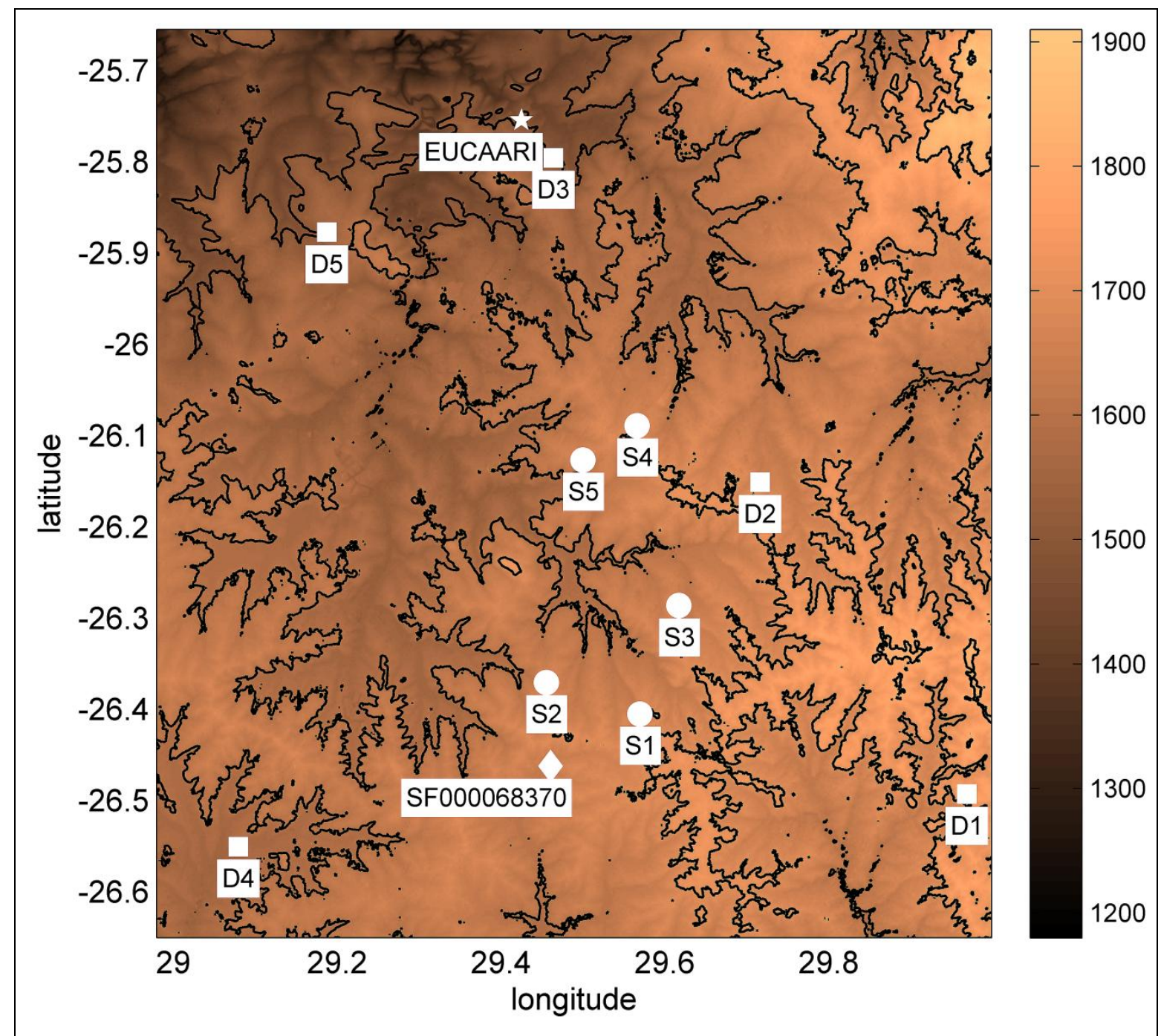

Figure 1. Digital elevation map of the Highveld Priority Area (HPA) in the Republic of South Africa. The map is based on the ASTER data base (http://www.gdem.aster.ersdac.or.jp/index.jsp). The horizontal data resolution is $1 \operatorname{arcsec}$ ( $30 \mathrm{~m}$ along longitude). Color shading gives the elevation in meters above mean sea level (scale bar at the right side). The Automatic Weather Stations (AWSs) deployed in the HPA micro-meteorological experiment - MMEH (S1 - S5: circles), DEA (D1 - D4: squares). Other stations (diamond and star) provide regular meteorological data in the area. 


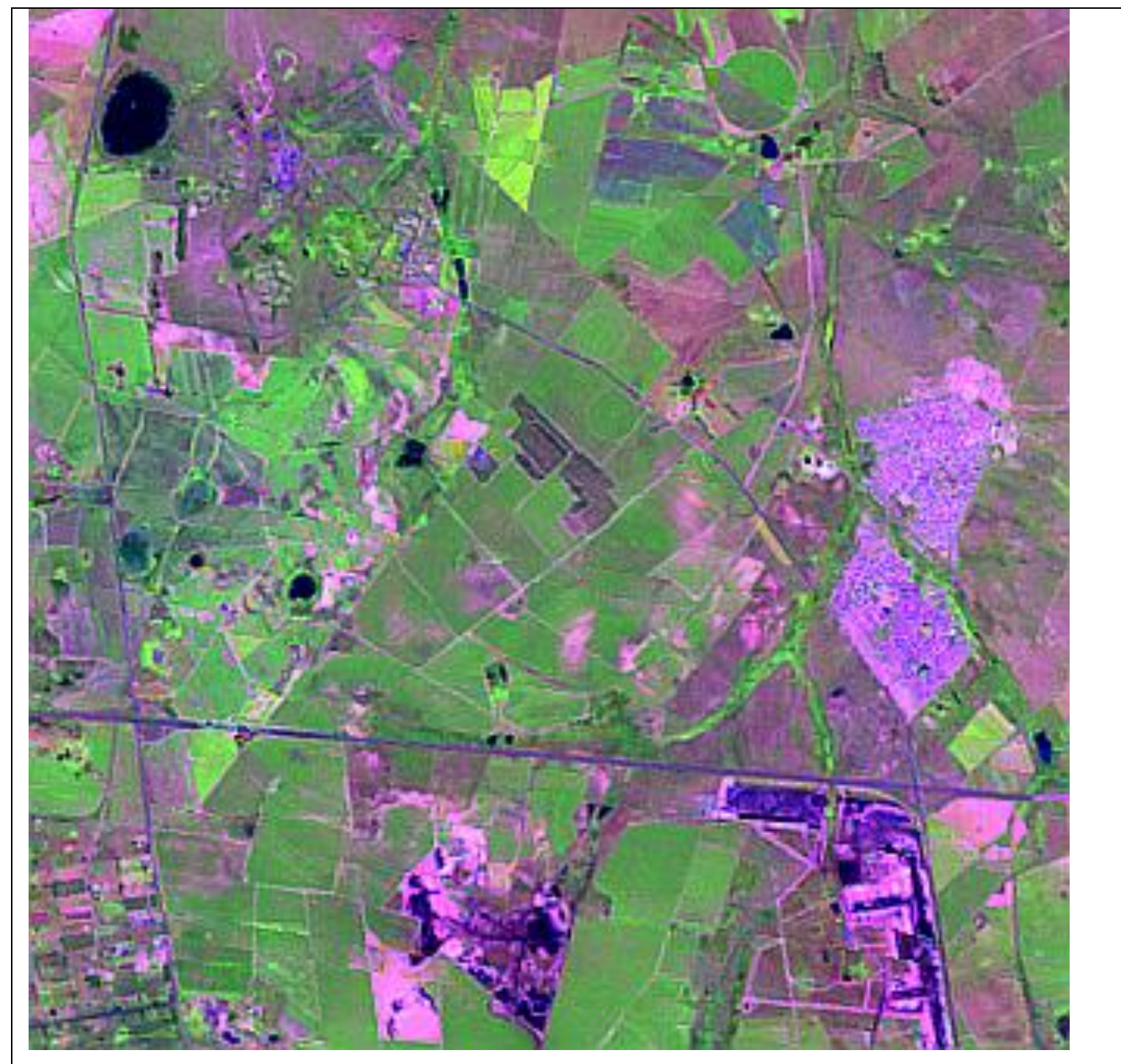

Figure 2. The Normalized Digital Vegetation Index (NDVI) for the tile e29s26 as obtained by the Landsat platform 7 with the sensor ETM+ at 03 July 2006. Pixel size $=$ $30 \mathrm{~m}$. The size of the shown area is $20.6 \mathrm{~km}$ by $20.6 \mathrm{~km}$. The data source is the FAO FRA Landsat Imagery Database http://globalmonitoring.sdstate.edu/projects/fao/index.html. Typical elements of surface heterogeneity are seen as: (1) green and yellow patches - agricultural fields (wheat and maze); (2) gray and black patches - coal carriers; (3) blue patches - water reservoirs; (4) magenta patches - build-up areas; and (5) reddish and grayish patches - natural bush and harvested fields. 


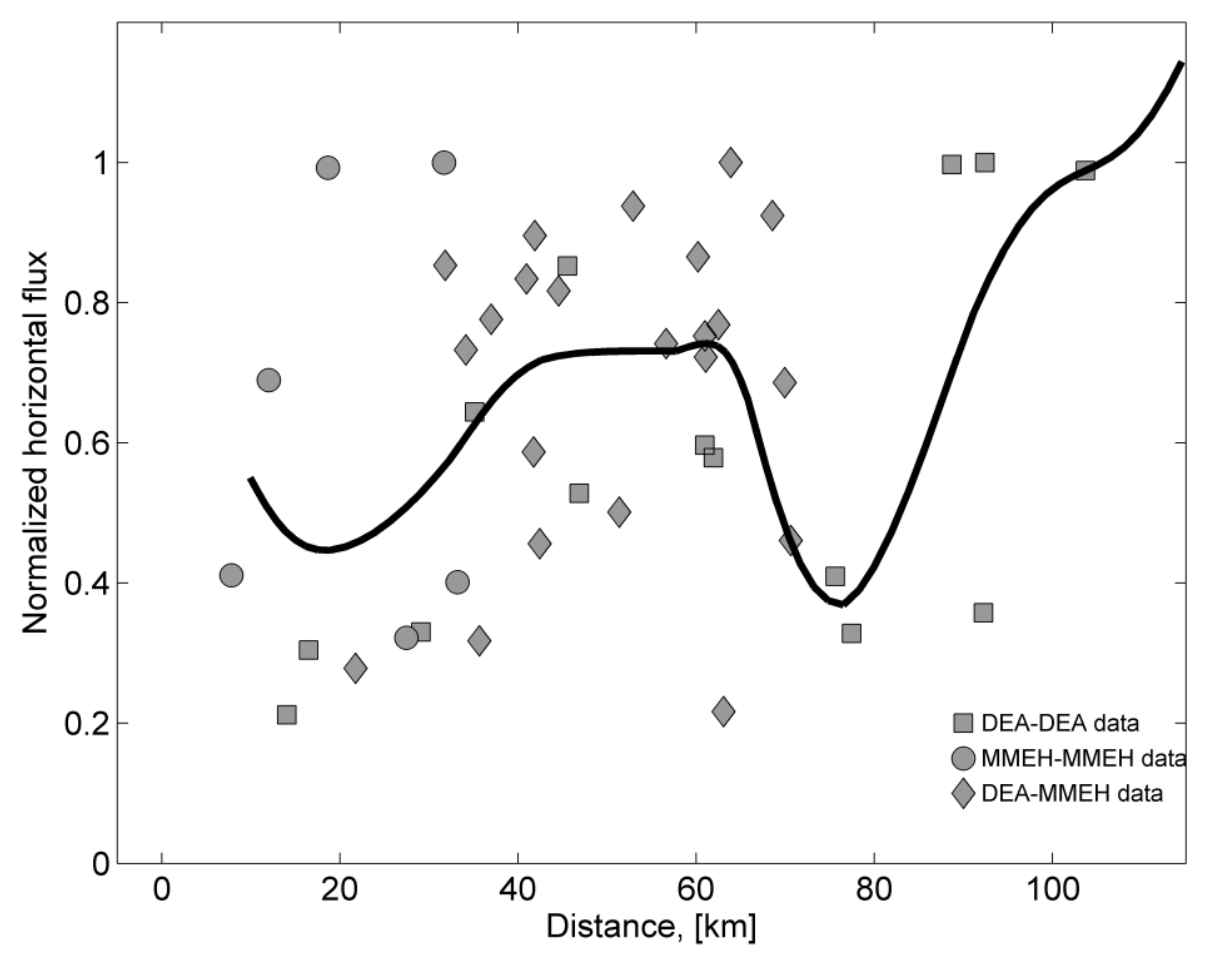

(a)

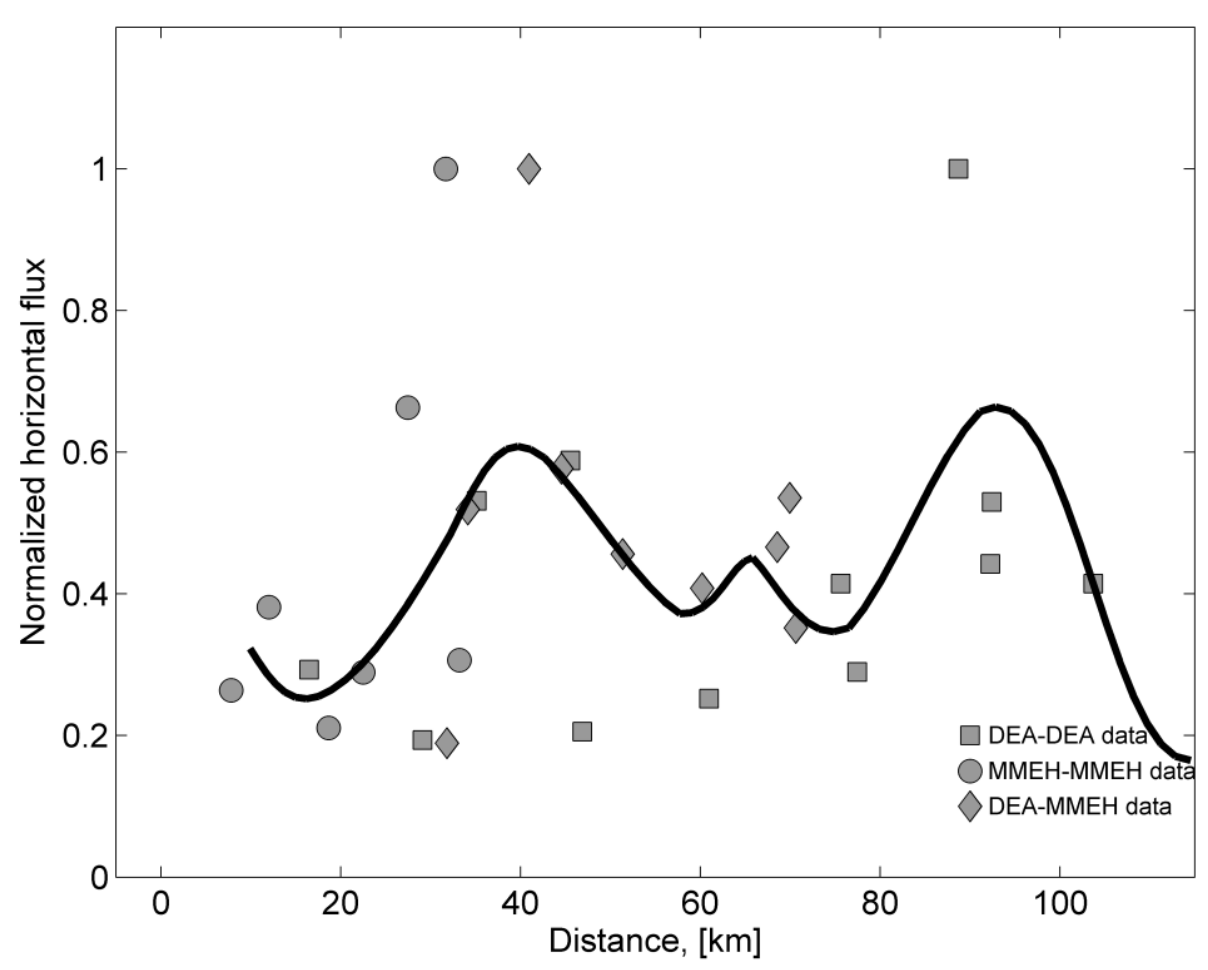

(b) 


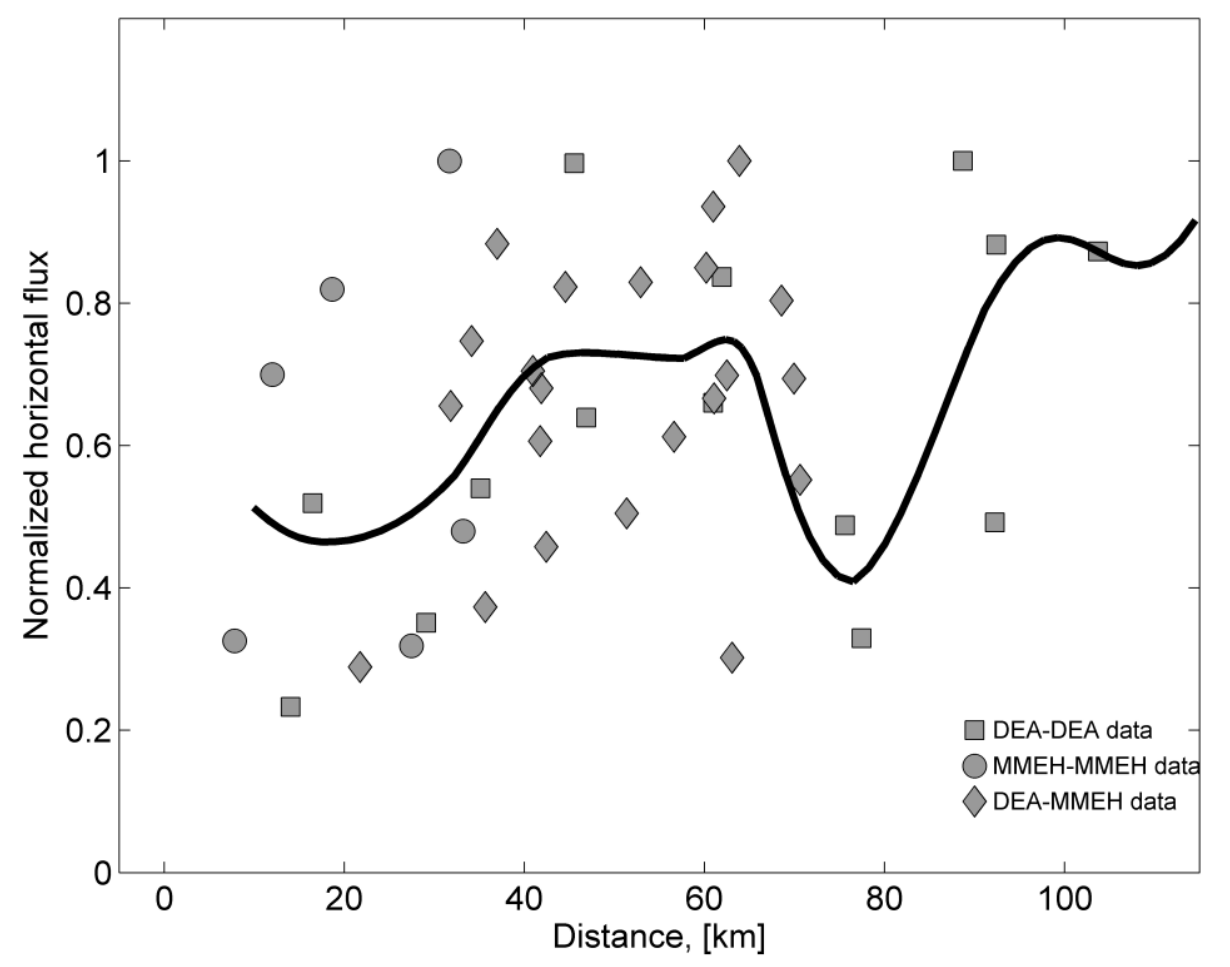

(c)

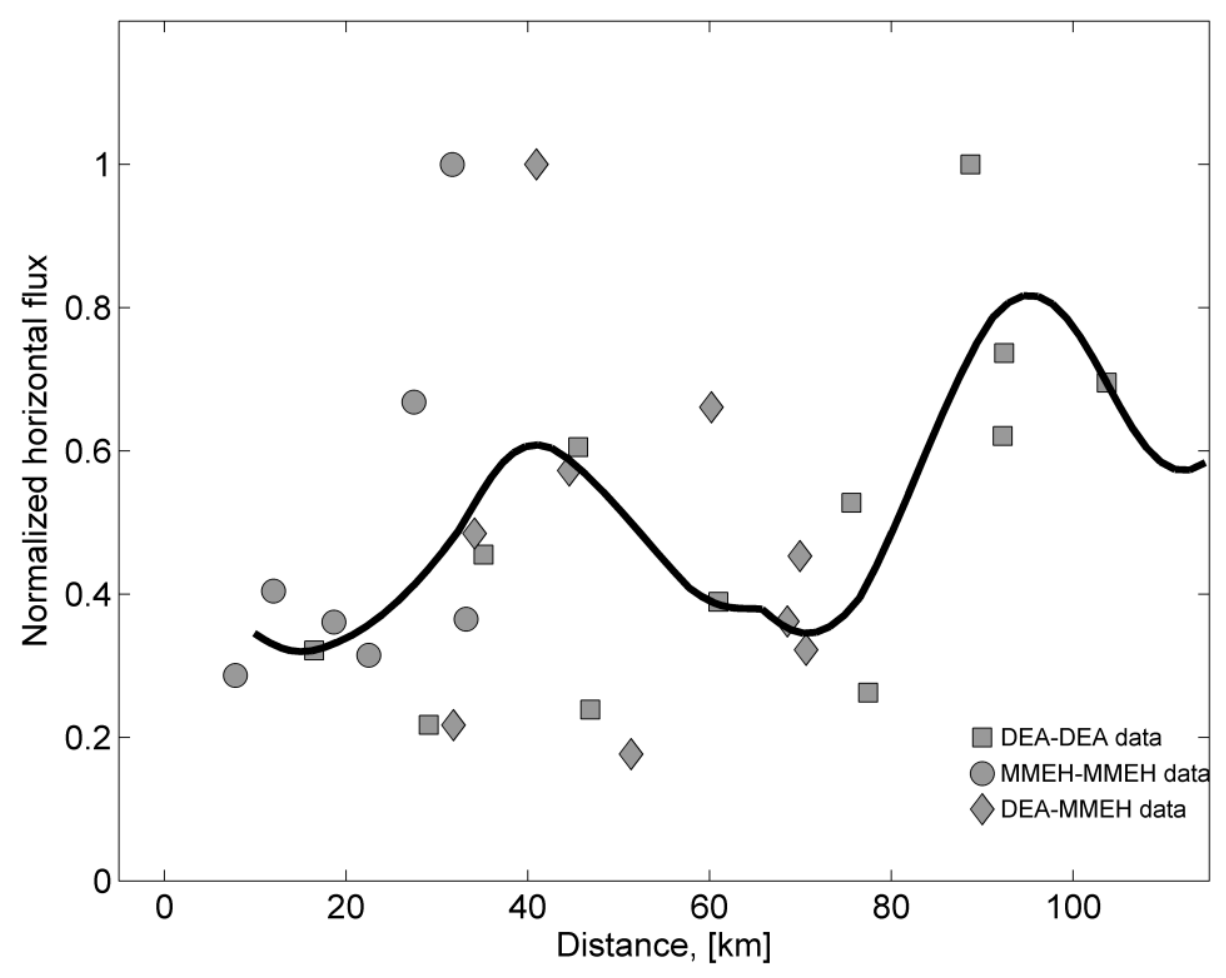

(d) 
Figure 3. Variation of the normalized horizontal temperature flux $\overline{U^{\prime} T^{\prime}}$ (a,b) and the normalized horizontal relative humidity flux $\overline{U^{\prime} R^{\prime}}$ (c,d) as obtained through Eq. (3) as a function of the distance between stations. The squares show fluxes obtained for the DEA data set; circles from the MMEH data set; diamonds from the mixed DEA (one station) MMEH (another station) data set. The bin-averaged dependence is shown by the black curve. Panels a and c show variation during the austral summer season and panels $\mathrm{b}$ and $\mathrm{d}$ variation during the austral winter season. 


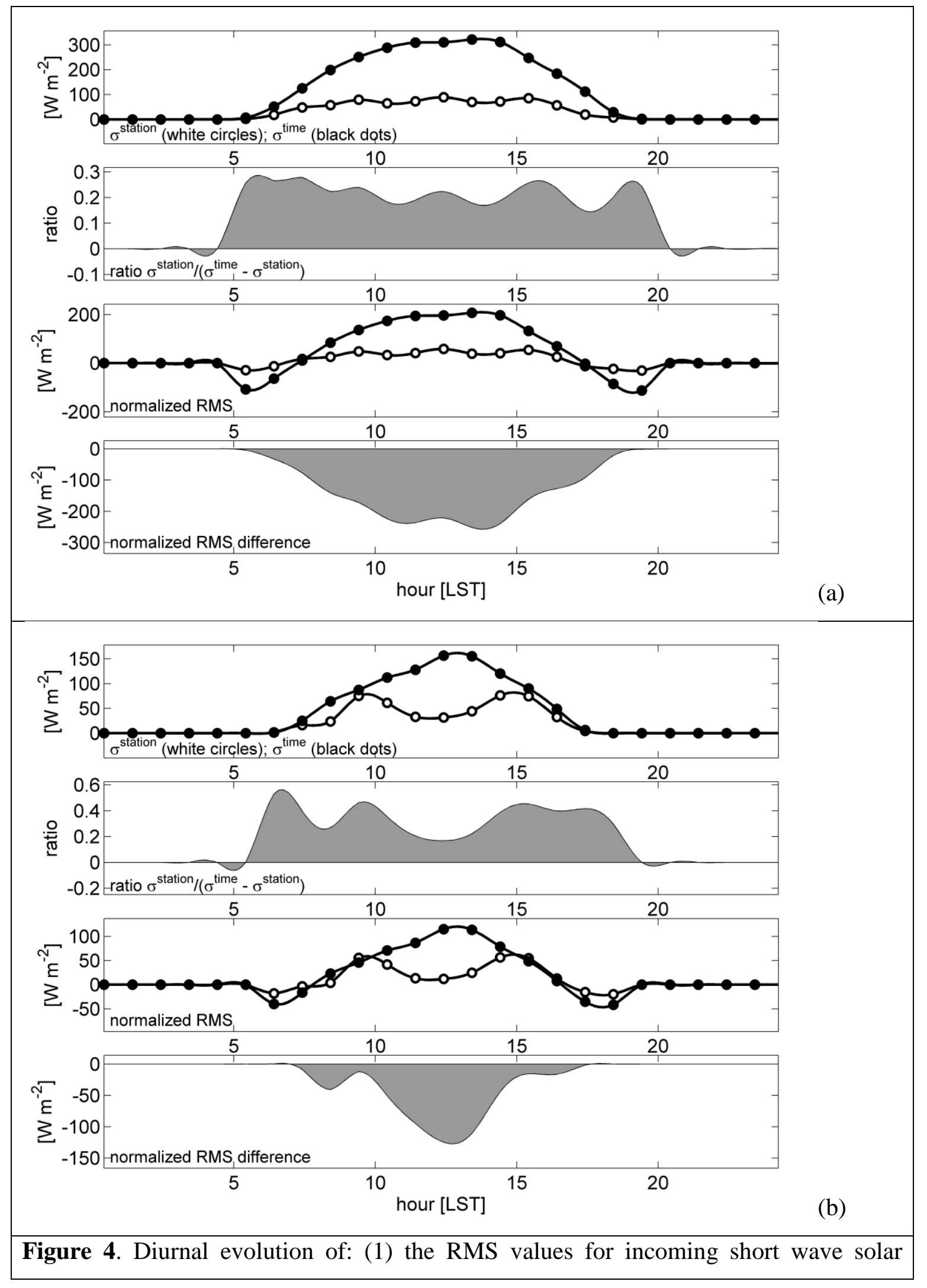


radiation, $\sigma_{S}^{\text {time }}$ (black dots) after $\mathrm{Eq}(4)$ and $\sigma_{S}^{\text {station }}$ (white circles) after Eq (5); (2) the ratio of variability $R_{S}$ after Eq. (6); (3) the normalized RMS values $\sigma_{S}^{\text {time }}-\overline{\sigma_{S}^{\text {time }}}$ (black dots) and $\sigma_{S}^{\text {station }}-\overline{\sigma_{S}^{\text {station }}}$ (white circles); (4) and their difference $D_{S}$ after Eq. (7). Panels $\mathrm{a}$ and $\mathrm{b}$ present the diurnal cycle for the austral summer and austral winter seasons, respectively. 

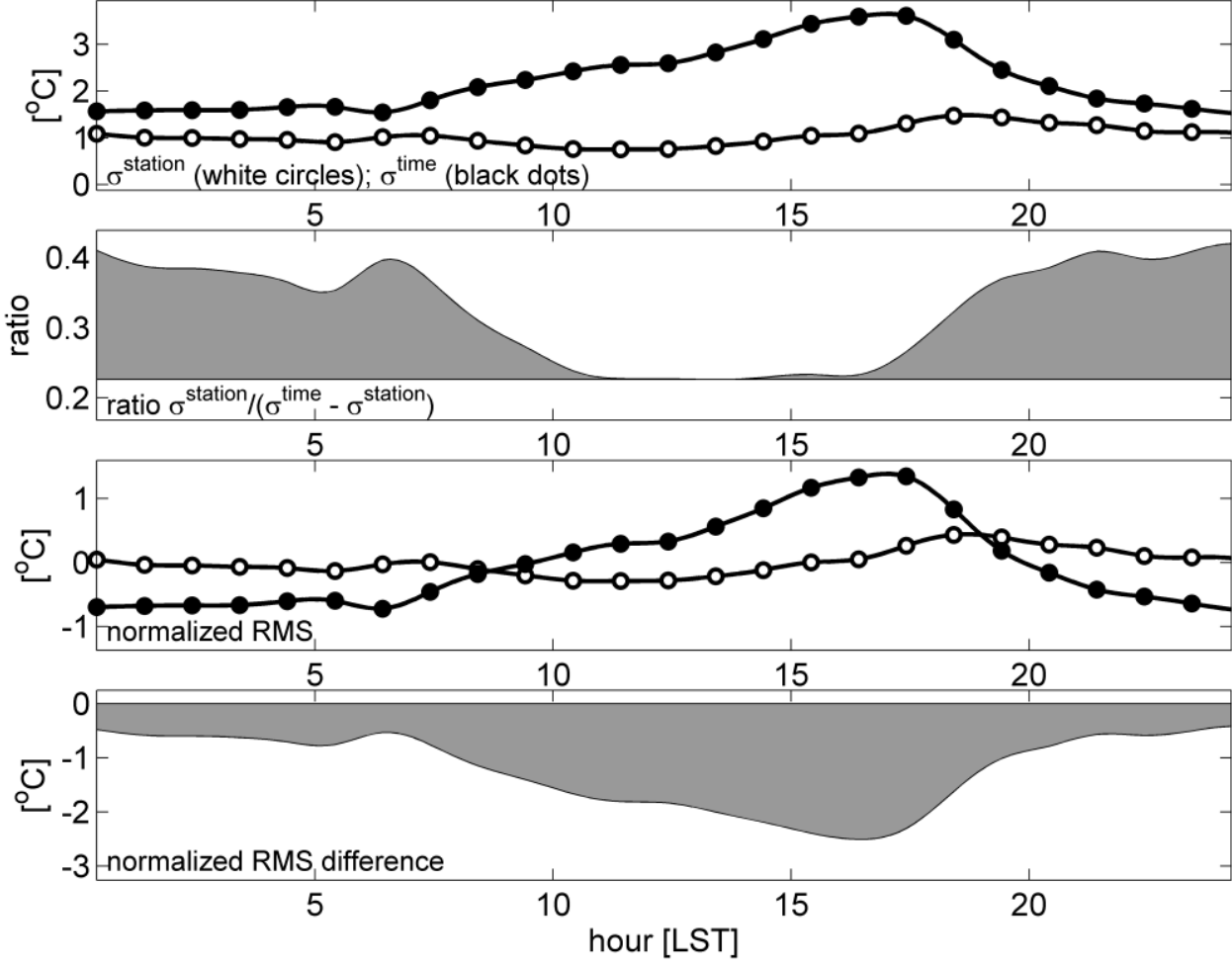

(a)
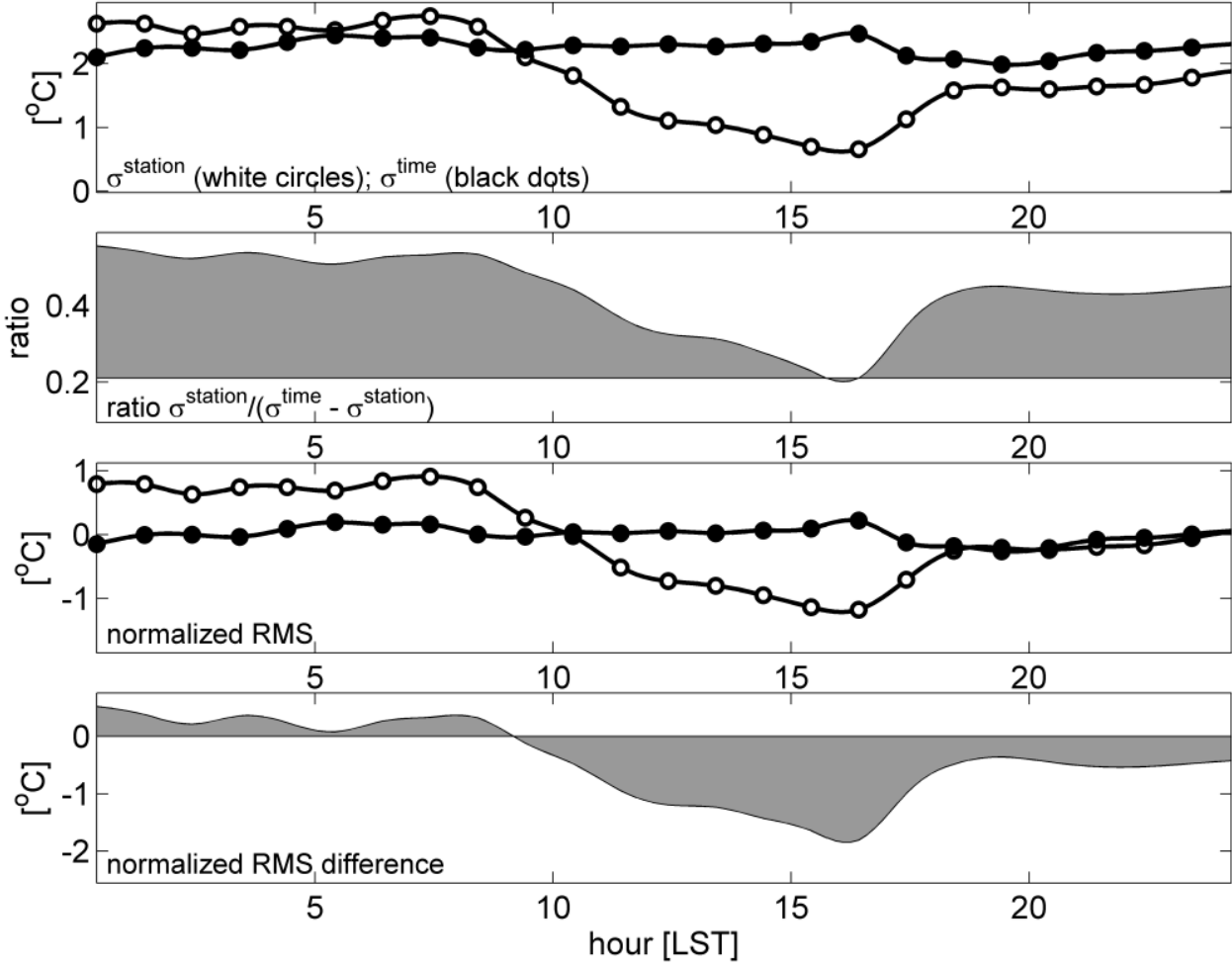

(b)

Figure 5. The same as in Figure 4 but for RMS values of near-surface air temperature 


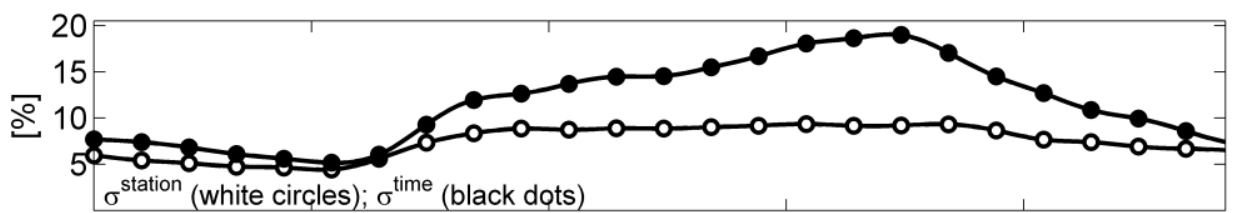

$5 \quad 10$

$15 \quad 20$
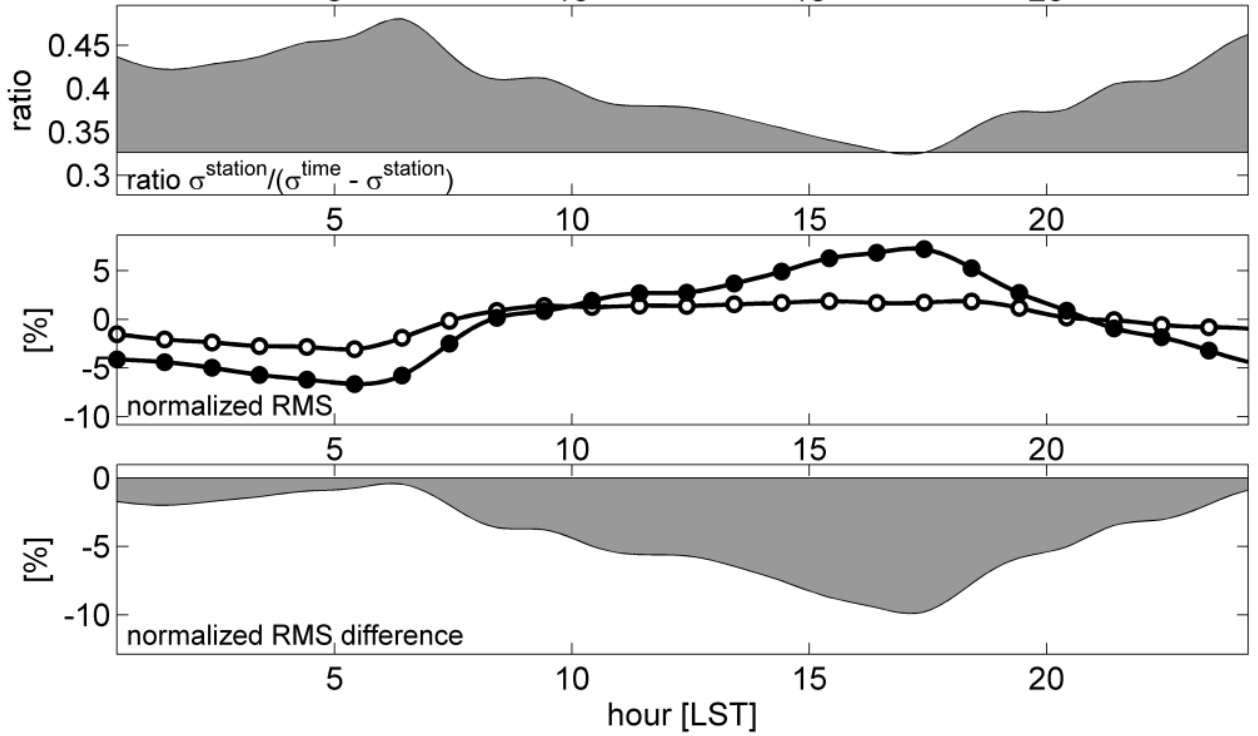

(a)
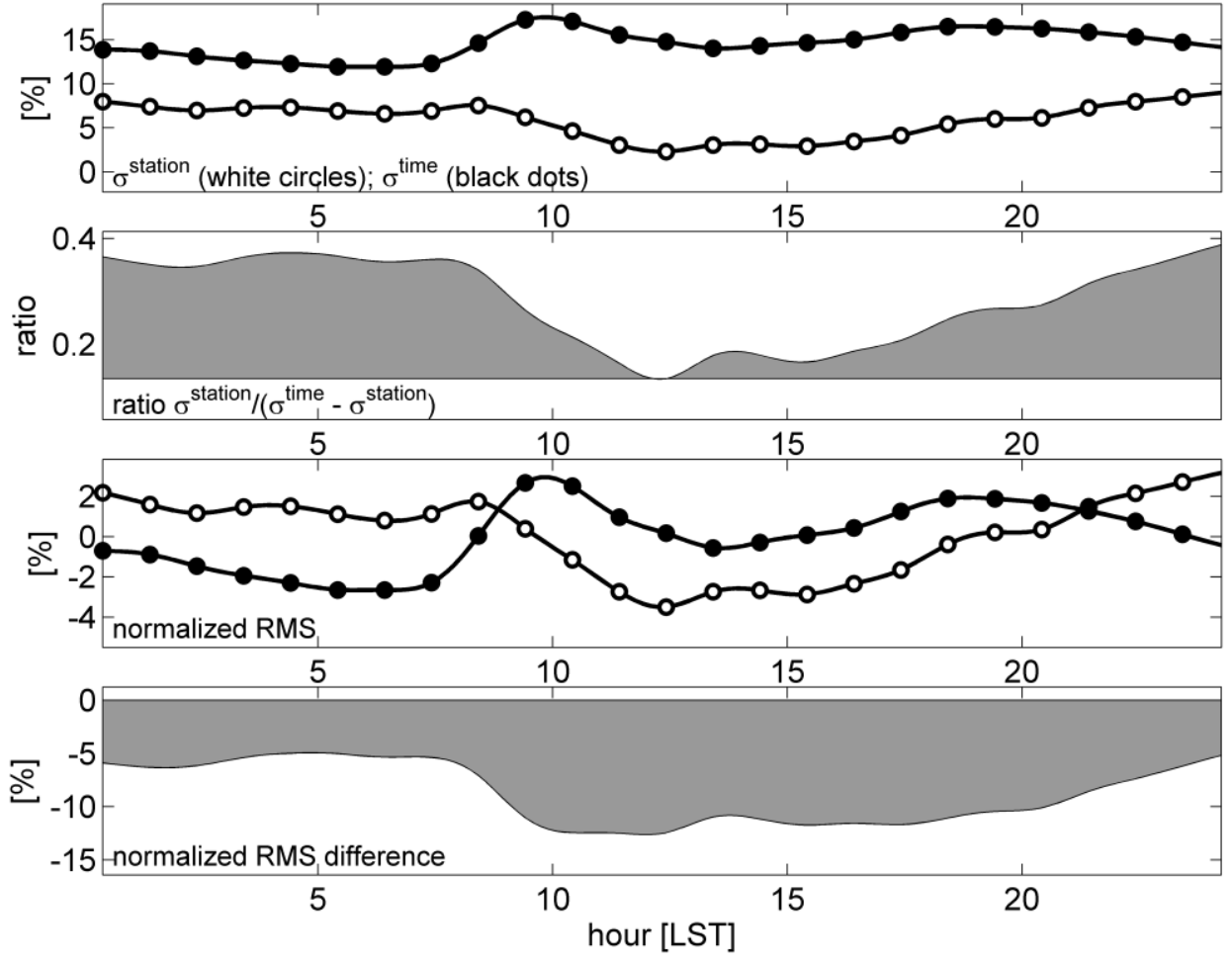

(b)

Figure 6. The same as in Figure 4 but for RMS values of relative humidity. 

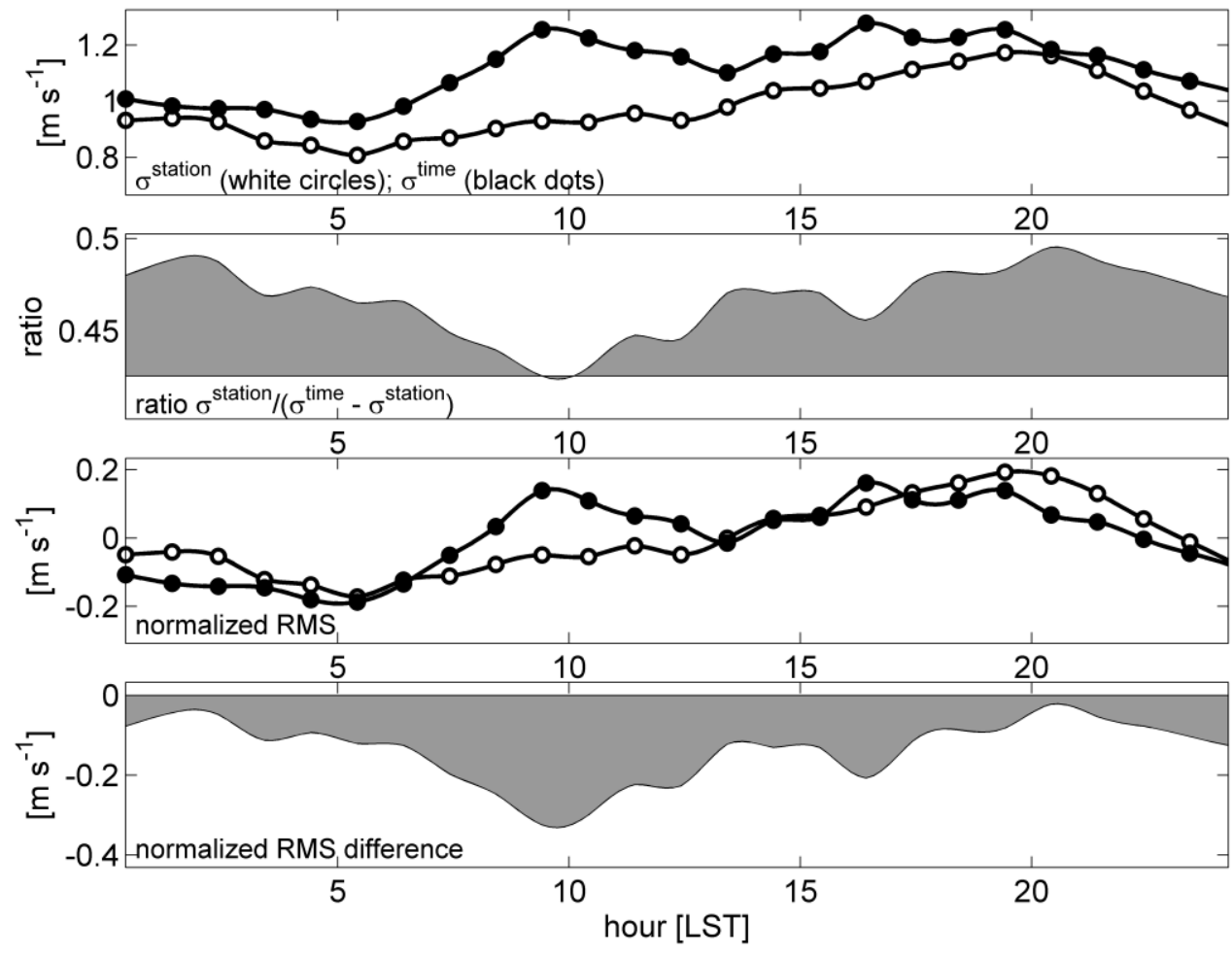

(a)
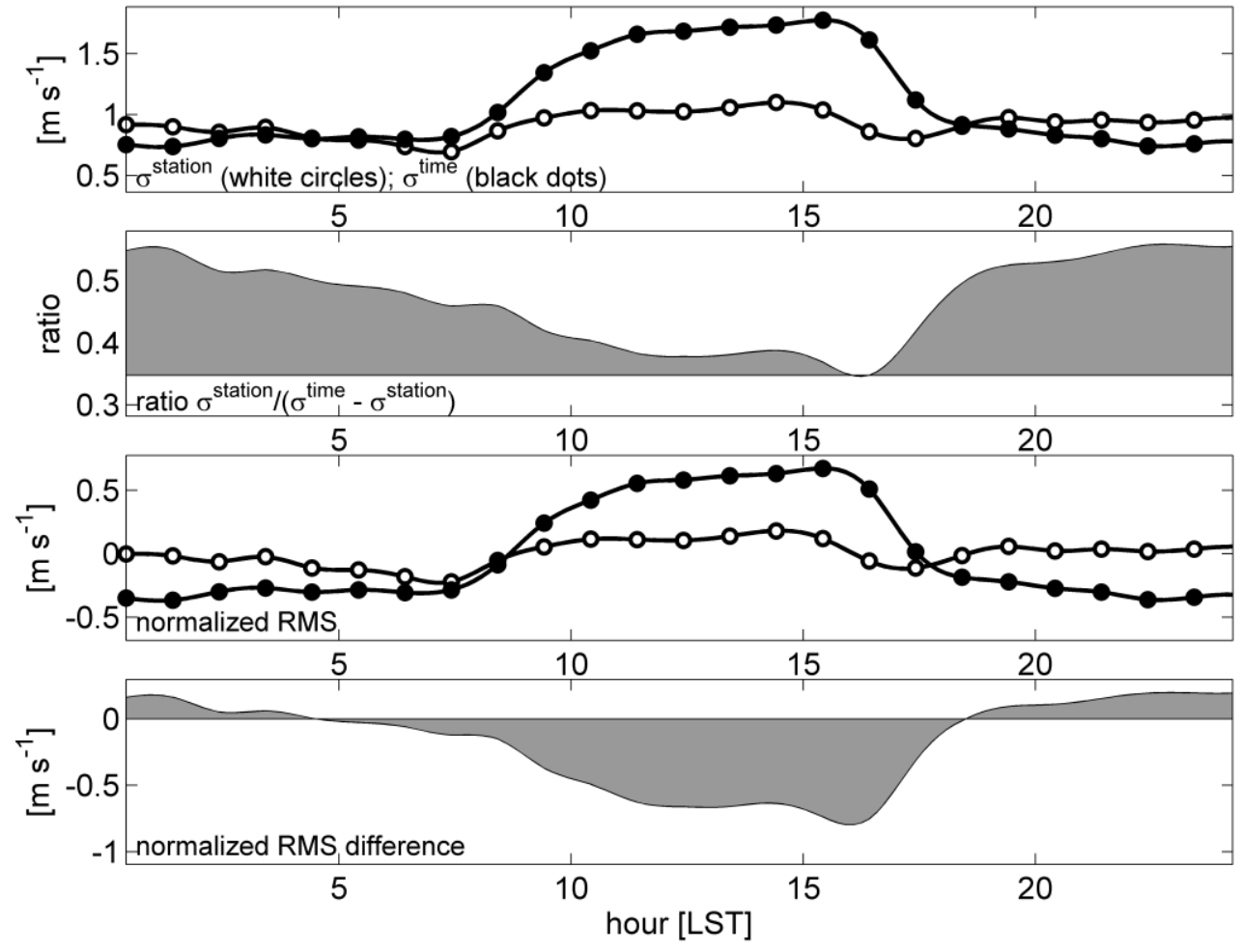

(b)

Figure 7. The same as in Figure 4 but for RMS values of wind speed. 


\section{Table captions}

Table 1. A list of Automatic Weather Stations (AWSs), their coordinates, altitudes and completeness of data in the observational records obtained.

Table 2. Distances between Automatic Weather Stations (AWSs) used in the Highveld Priority Area (HPA).

\section{Tables}

Table 1. The list of automatic meteorological stations, their coordinates, altitudes and completes of data in the database.

\begin{tabular}{|c|c|c|c|c|c|c|}
\hline \multirow[b]{2}{*}{ Station and farm name } & \multirow[b]{2}{*}{$\begin{array}{c}\text { Southern } \\
\text { latitude, } \\
\text { degrees }\end{array}$} & \multirow[b]{2}{*}{$\begin{array}{c}\text { Eastern } \\
\text { longitude, } \\
\text { degrees }\end{array}$} & \multirow[b]{2}{*}{$\begin{array}{c}\text { Altitude } \\
\text { above sea } \\
\text { level, } \mathbf{m}\end{array}$} & \multicolumn{3}{|c|}{ Completeness (\%) over the time period } \\
\hline & & & & 01.01.08-31.12.10 & 01.06.09-31.07.09 & 01.01.09-28.02.09 \\
\hline \multicolumn{7}{|l|}{ DEA stations } \\
\hline D1. Ermelo & 26.4930 & 29.9685 & 1760 & 55 & 100 & 60 \\
\hline D2. Hendrina & 26.1514 & 29.7162 & 1660 & 43 & 100 & 0 \\
\hline D3. Middleburg & 25.7960 & 29.4640 & 1510 & 47 & 100 & 80 \\
\hline D4. Secunda & 25.8776 & 29.1874 & 1570 & 50 & 100 & 90 \\
\hline D5. Witbank & 26.5507 & 29.0791 & 1500 & 47 & 100 & 90 \\
\hline \multicolumn{7}{|l|}{ MMEH stations } \\
\hline S1. Jan de Jager, Banklaagte & 26.4053 & 29.5691 & 1650 & 19 & 80 & 70 \\
\hline $\begin{array}{l}\text { S2. Anton van Tonder, } \\
\text { Yzervarkfontein }\end{array}$ & 26.3706 & 29.4550 & 1660 & 19 & 0 & 70 \\
\hline S3. Bram Jordan, Rietkuil & 26.2864 & 29.6169 & 1670 & 15 & 0 & 0 \\
\hline S4. Anton Pelse, Driefontein & 26.0892 & 29.5661 & 1706 & 50 & 100 & 100 \\
\hline S5. Daleen von Wieligh, Bultfontein & 26.1270 & 29.4999 & 1656 & 18 & 0 & 0 \\
\hline
\end{tabular}


Table 2. Distances between Automatic Weather Stations (AWSs) used in the Highveld Priority Area (HPA).

\begin{tabular}{|l|l|l|l|l|l|l|l|l|l|}
\hline & S1 & S2 & S3 & S4 & S5 & D1 & D2 & D3 & D4 \\
\hline S2 & 12 & - & - & - & - & - & - & - & - \\
S3 & 14 & 19 & - & - & - & - & - & - & - \\
S4 & 35 & 33 & 23 & - & - & - & - & - & - \\
S5 & 32 & 27 & 21 & 8 & - & - & - & - & - \\
D1 & 41 & 53 & 42 & 60 & 62 & - & - & - & - \\
D2 & 32 & 36 & 18 & 17 & 22 & 46 & - & - & - \\
D3 & 69 & 64 & 57 & 34 & 37 & 92 & 47 & - & - \\
D4 & 51 & 42 & 61 & 71 & 63 & 89 & 77 & 92 & - \\
D5 & 70 & 61 & 62 & 45 & 42 & 104 & 61 & 29 & 76 \\
\hline
\end{tabular}




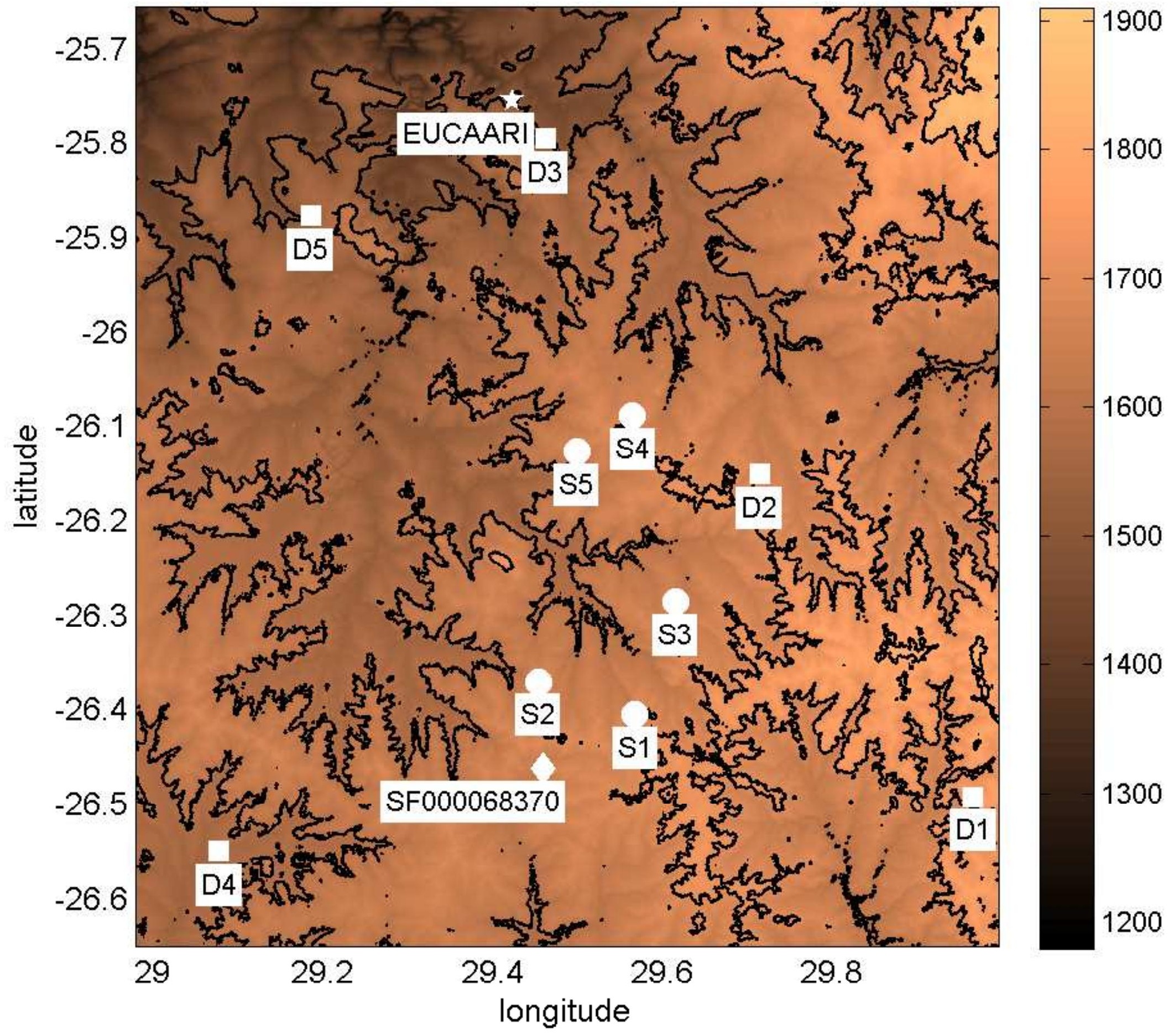




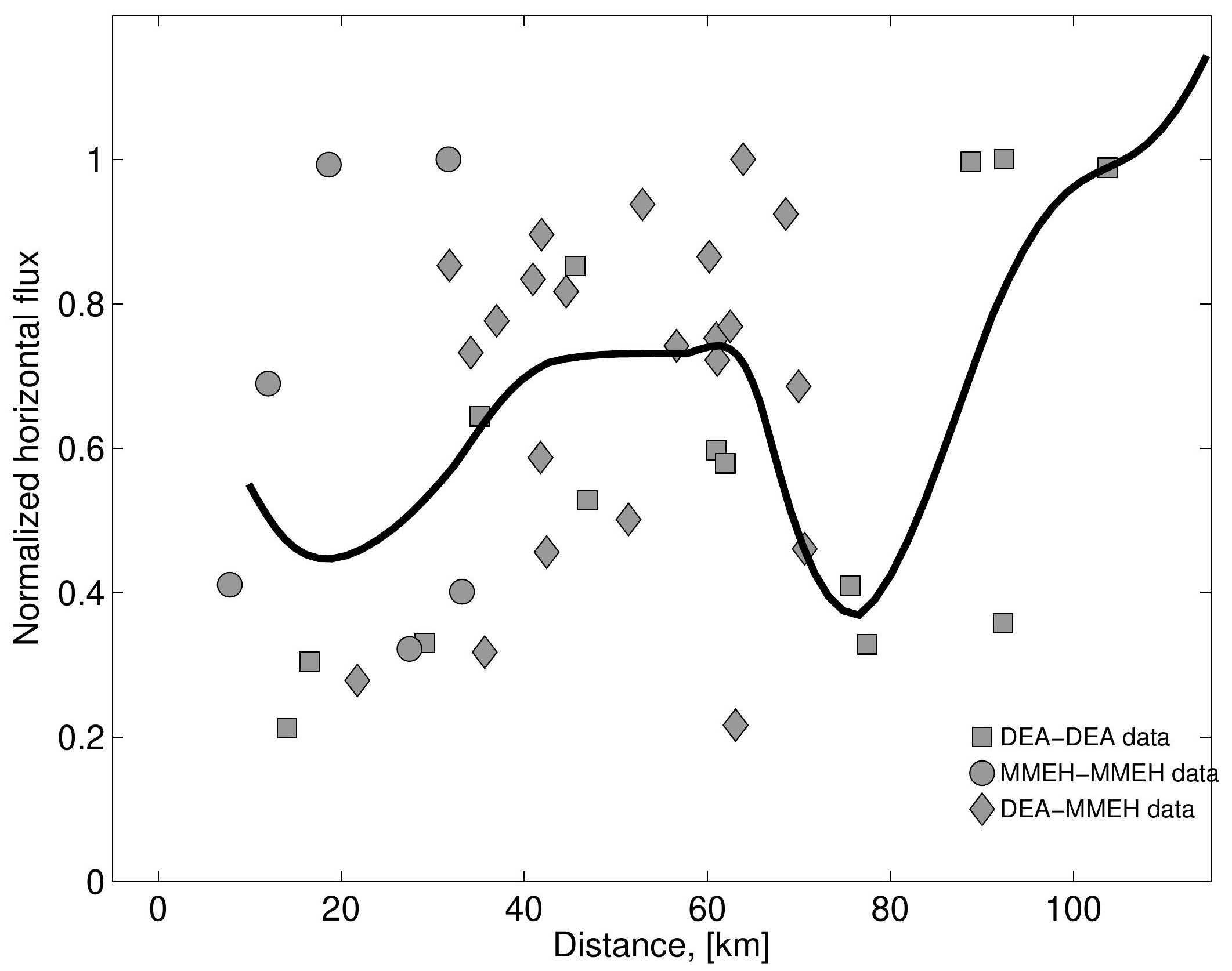




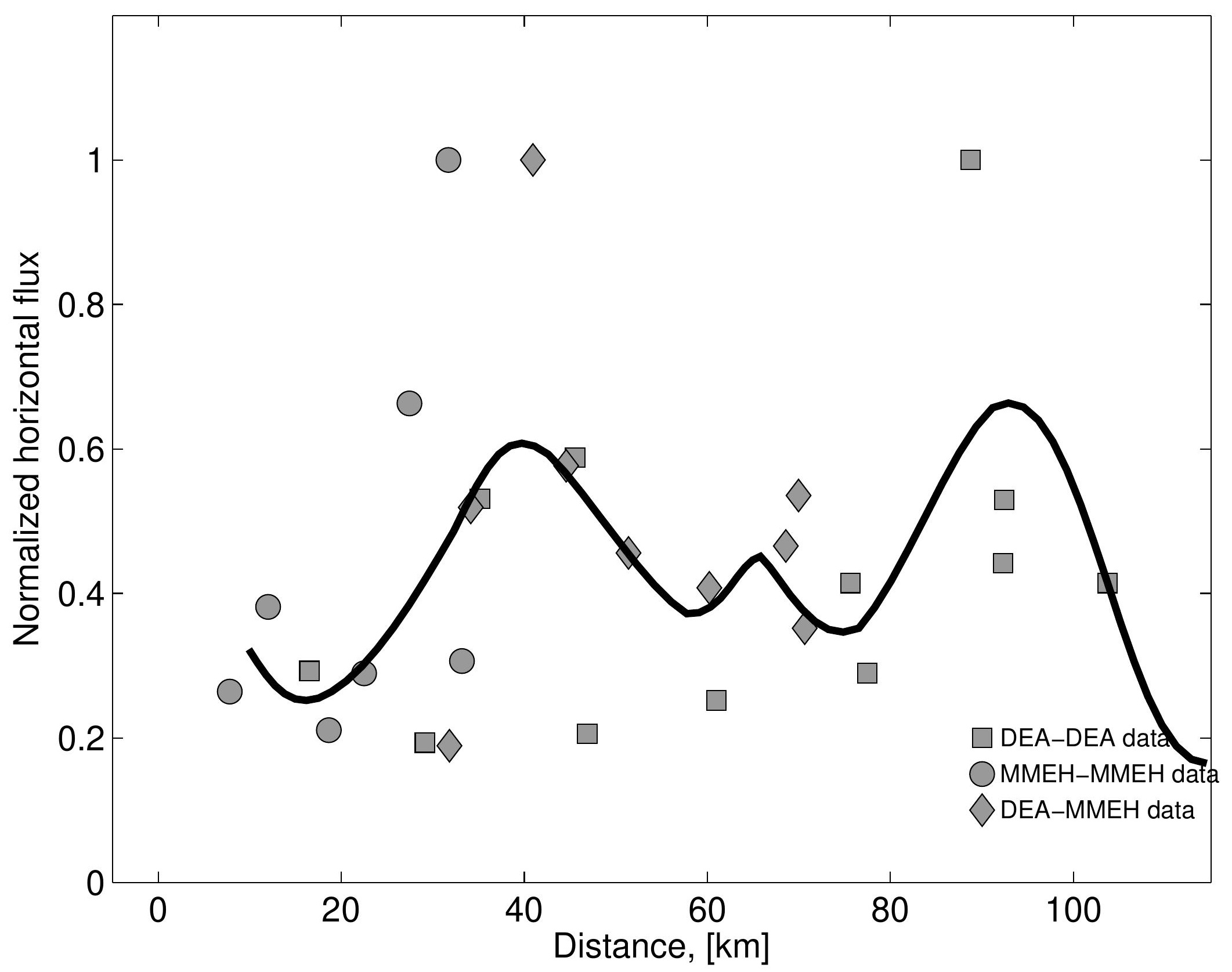




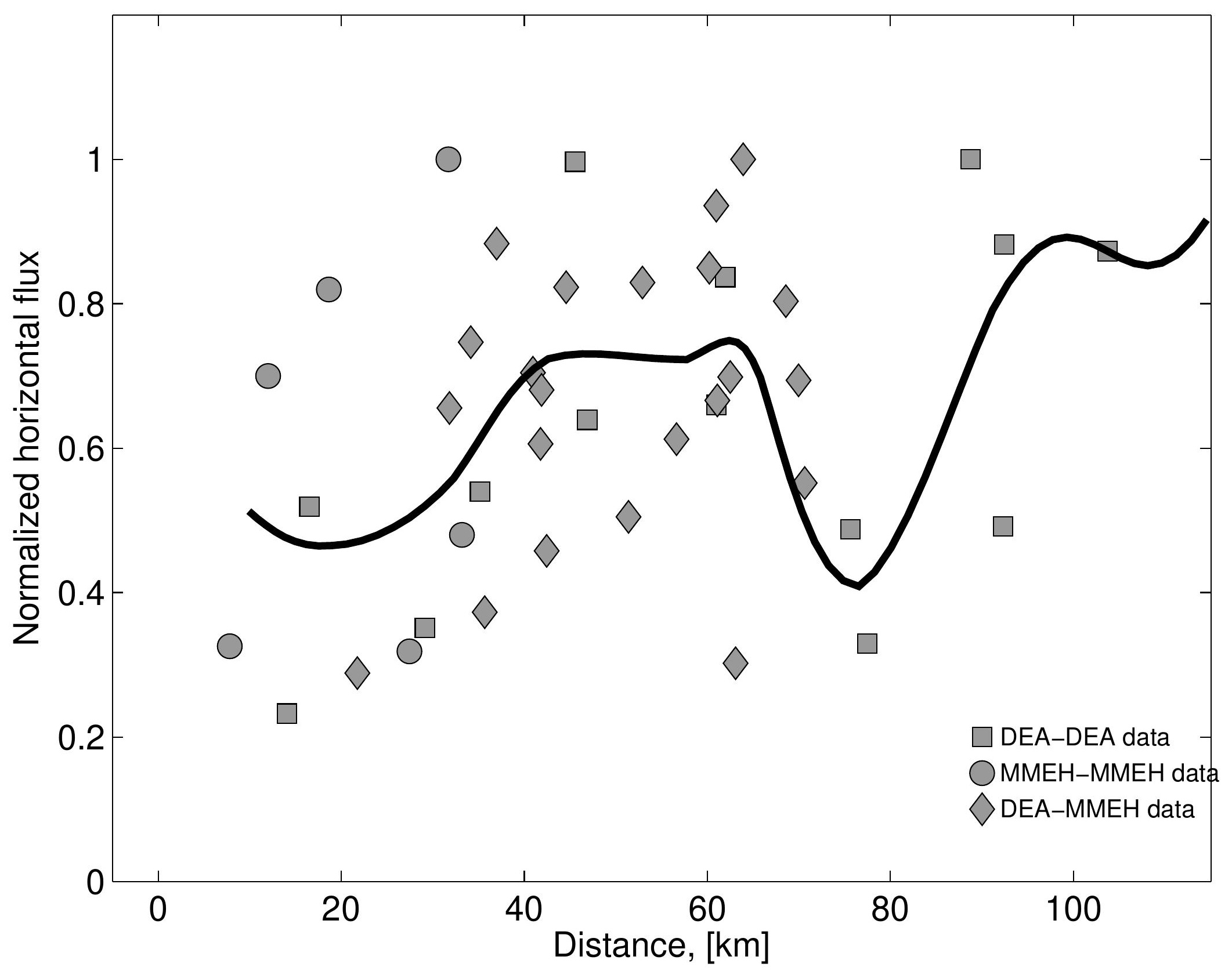




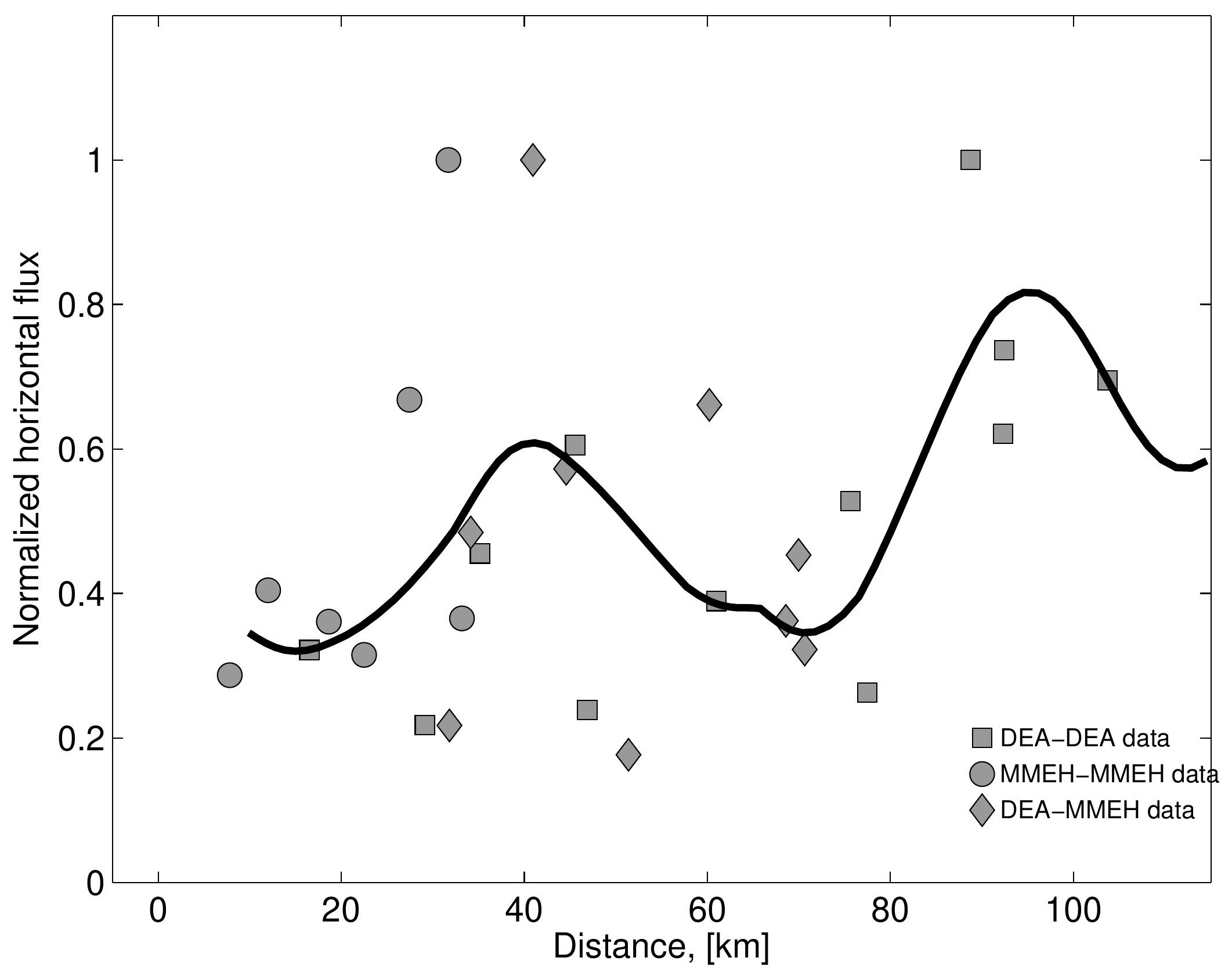




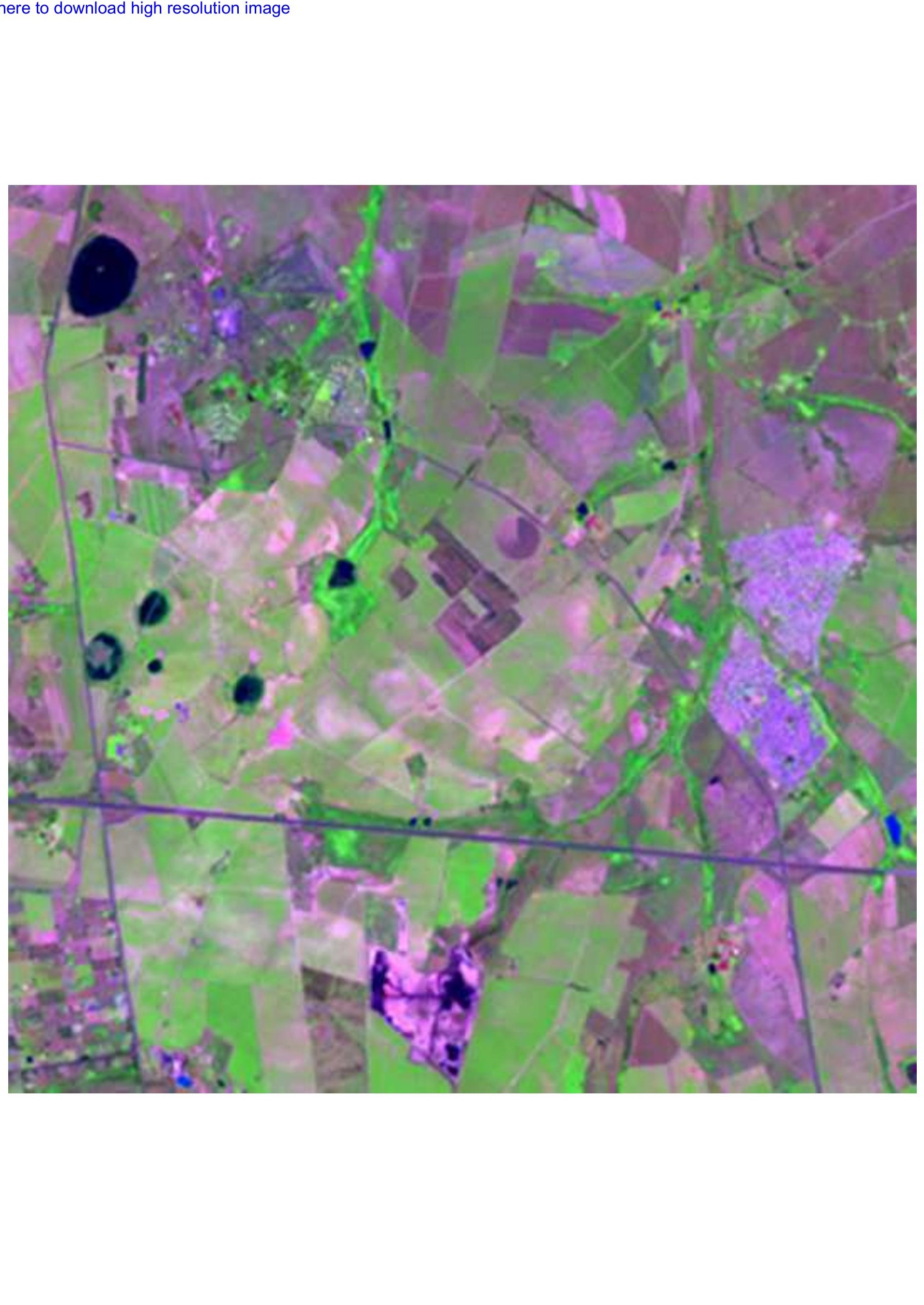

.



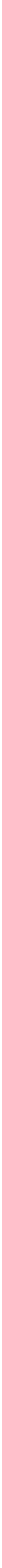

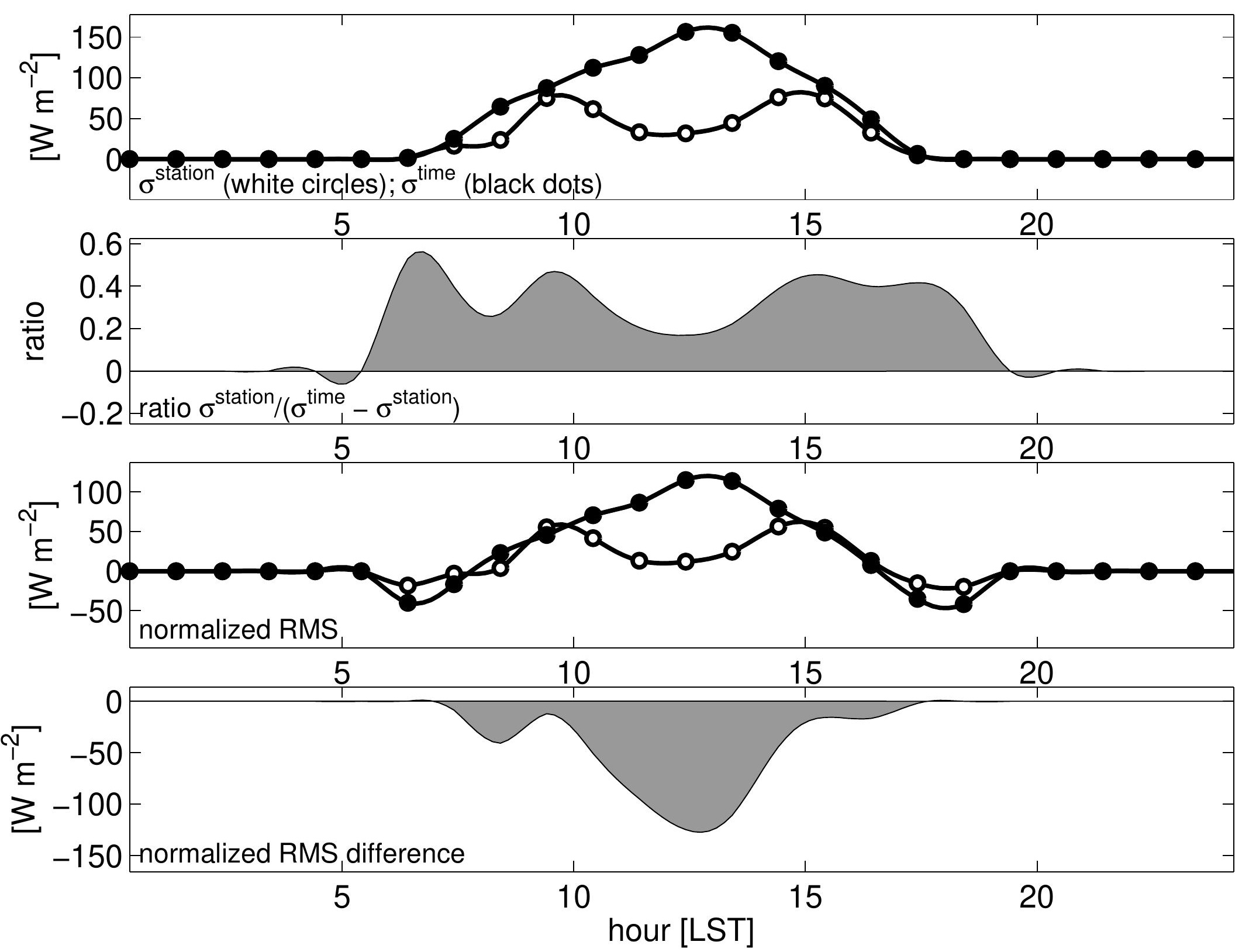

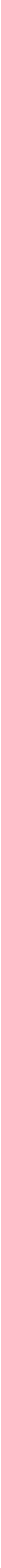

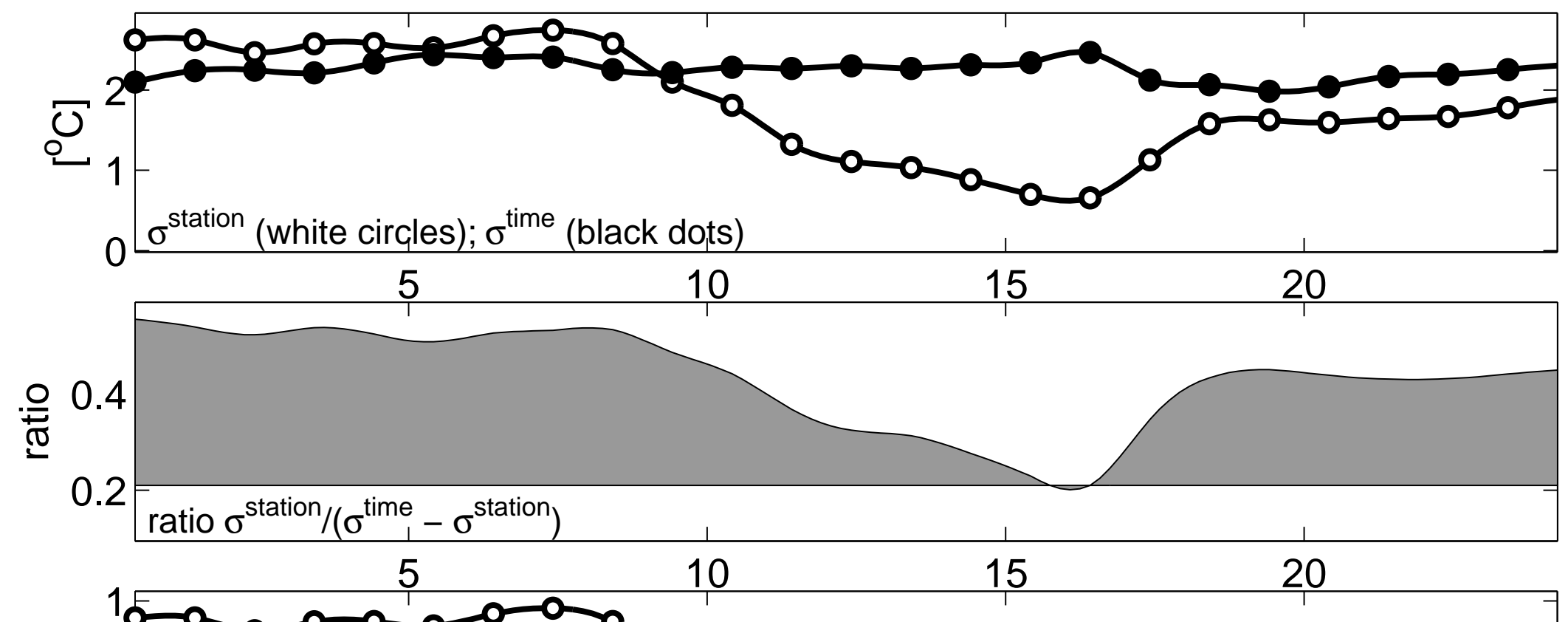

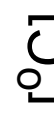

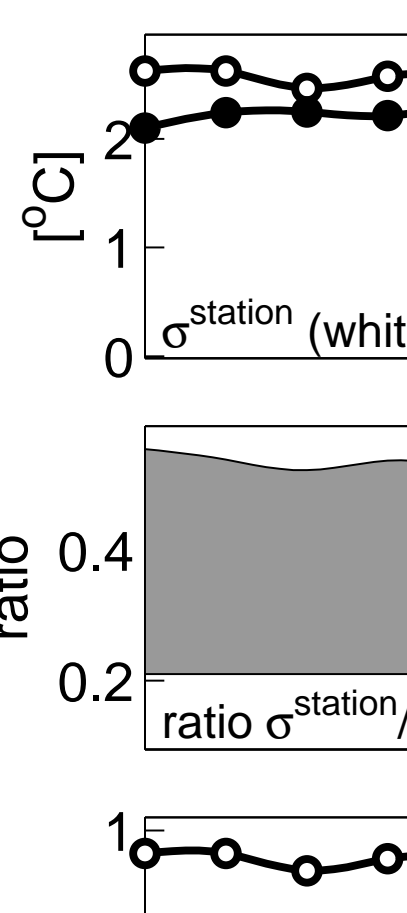

0

$-1$

normalized RMS,
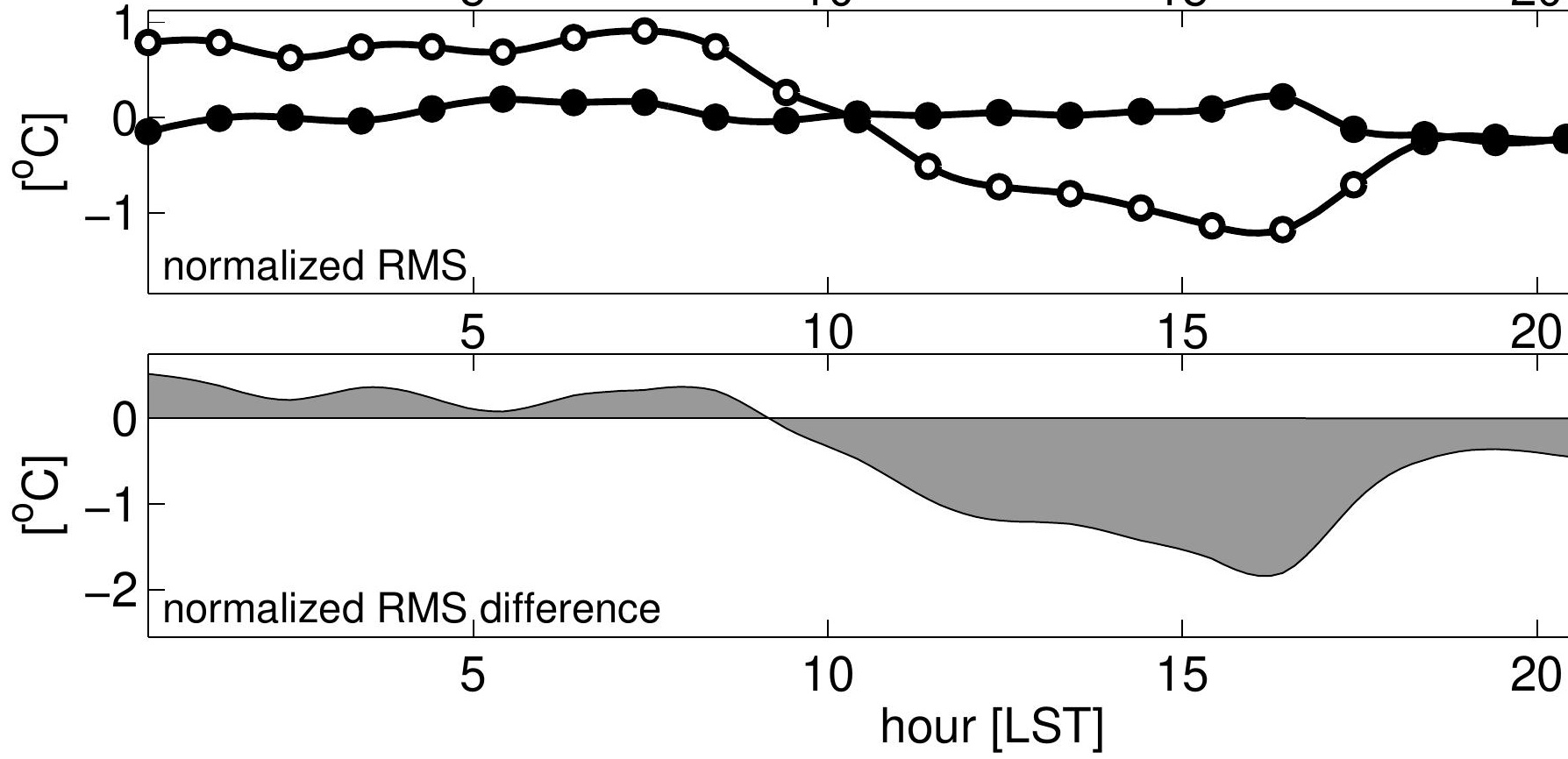

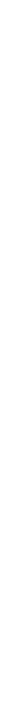

0.3 ratio $\sigma^{\text {station }} /\left(\sigma^{\text {time }}-\sigma^{\text {station }}\right)$

$$
5
$$
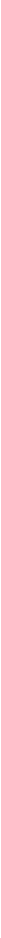


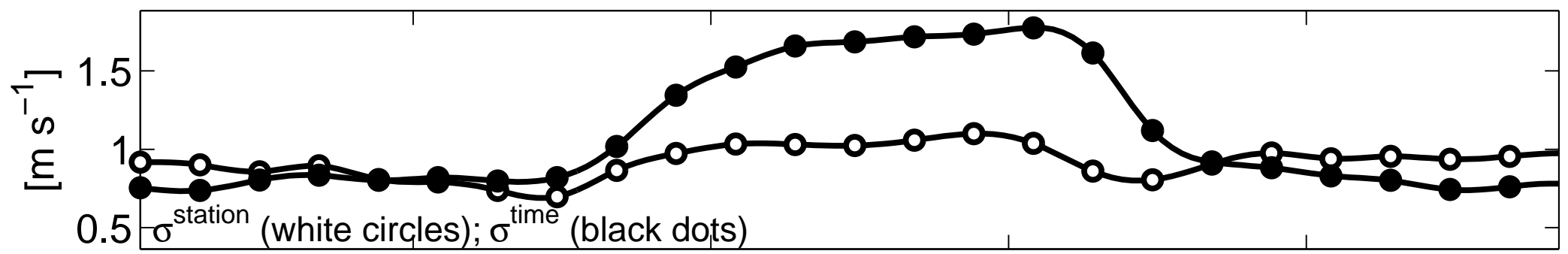

$0.5-\sigma^{\text {station }}$ (white circles); $\sigma^{\text {time }}$ (black dots)
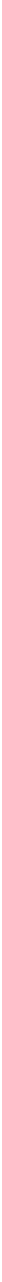